\title{
Pectobacterium carotovorum Elicits Plant Cell Death with DspE/F but the P. carotovorum DspE Does Not Suppress Callose or Induce Expression of Plant Genes Early in Plant-Microbe Interactions
}

\author{
Hye-Sook Kim, ${ }^{1}$ Phanit Thammarat, ${ }^{3}$ Steven A. Lommel, ${ }^{3}$ Clifford S. Hogan, ${ }^{2}$ and Amy O. Charkowski ${ }^{2}$ \\ ${ }^{1}$ Department of Biochemistry and Molecular Biology, University of Chicago, 929 E. 57th Street, W225 Chicago, IL 60637, \\ U.S.A.; ${ }^{2}$ Department of Plant Pathology University of Wisconsin-Madison, 1630 Linden Dr., Madison, WI 53706, U.S.A.; \\ Department of Plant Pathology, North Carolina State University, Box 7342, Raleigh, NC 27695-7342, U.S.A.
}

Submitted 2 July 2010. Accepted 8 March 2011.

\begin{abstract}
The broad-host-range bacterial soft rot pathogen Pectobacterium carotovorum causes a DspE/F-dependent plant cell death on Nicotiana benthamiana within $24 \mathrm{~h}$ postinoculation (hpi) followed by leaf maceration within 48 hpi. $P$. carotovorum strains with mutations in type III secretion system (T3SS) regulatory and structural genes, including the $d s p E / F$ operon, did not cause hypersensitive response (HR)like cell death and or leaf maceration. A strain with a mutation in the type II secretion system caused HR-like plant cell death but no maceration. $P$. carotovorum was unable to impede callose deposition in $N$. benthamiana leaves, suggesting that $P$. carotovorum does not suppress this basal immunity function. Within $24 \mathrm{hpi}$, there was callose deposition along leaf veins and examination showed that the pathogen cells were localized along the veins. To further examine HR-like plant cell death induced by $P$. carotovorum, gene expression profiles in $N$. benthamiana leaves inoculated with wild-type and mutant $P$. carotovorum and Pseudomonas syringae strains were compared. The $N$. benthamiana gene expression profile of leaves infiltrated with Pectobacterium carotovorum was similar to leaves infiltrated with a Pseudomonas syringae T3SS mutant. These data support a model where Pectobacterium carotovorum uses the T3SS to induce plant cell death in order to promote leaf maceration rather than to suppress plant immunity.
\end{abstract}

To cope with microbial attacks, plants have evolved a sophisticated network of adaptive responses, including physical barriers and production of antimicrobial metabolites and proteins. Plant innate immunity is activated by the perception of pathogen-associated molecular patterns (PAMPs) such as flagellin, lipopolysaccharide, peptidoglycan, and EF-Tu, which are recognized by transmembrane pattern-recognition receptors (Abramovitch et al. 2006; Bent and Mackey 2007; Jones and

Current address for H.-S. Kim: Department of Biochemistry and Molecular Biology, University of Chicago, 929 East 57th St., Chicago, IL 60637, U.S.A.

Corresponding author: A. O. Charkowski; Telephone: +1.608 .262 .7911 ; Fax: +1.608.263.2626; E-mail: acharkowski@wisc.edu

* The $\boldsymbol{e}$-Xtra logo stands for "electronic extra" and indicates that one supplementary figure is published online and Figures 2 and 3 appear in color online.
Dangl 2006). This leads to rapid activation of multiple defense responses, such as cell wall reinforcement by callose deposition (DebRoy et al. 2004; Hauck et al. 2003; Oh and Collmer 2005) and production of reactive oxygen species (Zhang et al. 2007), mitogen-activated protein kinase (MAPK) signaling cascades (Asai et al. 2002), and induction of defense-related genes.

Many gram-negative plant- and animal-pathogenic bacteria deliver virulence effector proteins directly into eukaryotic host cells through the type III secretion system (T3SS). Once delivered, effector proteins alter the host immune system and promote pathogenesis (Grant et al. 2006). These secreted proteins may also trigger a second branch of the plant immune system, denoted as effector-triggered immunity (ETI). Numerous resistance $(\mathrm{R})$ proteins directly or indirectly detect pathogen effectors and then rapidly activate defense responses, including oxidative burst, protein kinase activity, ion channel gating, and defense-associated gene expression (Bent and Mackey 2007; Chisholm et al. 2006). The hypersensitive response (HR), characterized by localized cell death at the site of infection, is also a common result of ETI. Thus, each effector appears to play at least one of three roles in virulence: inhibition of PAMP-triggered immunity (PTI), inhibition of ETI, or elicitation of plant cell death.

Among the phytopathogenic bacteria, multiple classes of T3SS gene clusters and numerous categories of effectors have been described. The T3SS effector avirulence (Avr)E (synonyms include DspE, DspA, and WtsE), is unusual in that it is widespread among Pseudomonas, Pantoea, Dickeya, Pectobacterium, and Erwinia spp., and it is always associated with a single category of T3SS. Genes encoding AvrE orthologs are commonly found in two-gene operons, with a chaperone, AvrF (also called DspF, DspB, and WtsF) encoded directly after avrE. AvrF may be involved in both translocation and AvrE stability in the bacterium (Gaudriault et al. 2002; Ham et al. 2006; Triplett et al. 2009). In Pseudomonas syringae, the T3 effector AvrE blocks PAMP-induced callose deposition along the cell-wall to enhance virulence on host plants (DebRoy et al. 2004). The DspE/WtsE orthologs encoded by Erwinia amylovora and Pantoea stewartii subsp. stewartii suppresses salicylic acid (SA)-mediated host defenses and cause cell death in host and non-host leaves (Boureau et al. 2005; DebRoy et al. 2004; Ham et al. 2008, 2009). This effector is required for pathogenicity by E. amylovora on apple leaves and pear fruit (Bogdanove et al. 1998a) and by Pantoea stewartii subsp. 
stewartii on corn leaves (Ham et al. 2006) but makes only a minor contribution to Pectobacterium atrosepticum virulence on potato stems and tubers (Holeva et al. 2004).

Compared with the swift progress during the last few decades in understanding effector biology of hemibiotrophic Pseudomonas spp. interactions with plants, little is known about the role effectors play in the pathogenesis of necrotrophic bacterial pathogens, such as Pectobacterium spp. The genus Pectobacterium includes four necrotrophic soft rot agents: $P$. atrosepticum, $P$. betavasculorum, $P$. carotovorum, and $P$. wasabiae and is pathogenic to species in over 35\% of plant orders (Gardan et al. 2003; Ma et al. 2007). Pectobacterium spp. are primarily known for causing root and tuber rots but also infect leaves of numerous species, including monocots such as calla lily and dicots such as poppy, lettuce, and marigold (Aranda et al. 2008; Ma et al. 2007). Even in species such as potato, when stem and tuber infections are typical, the bacteria will move from the stem into plant leaves, causing them to decay.

Pectobacterium spp. symptom development is primarily caused by plant cell-wall-degrading enzymes secreted through a type II secretion system (T2SS). These enzymes include multiple pectinases, polygalactronases, and cellulases (Bell et al. 2004; Perombelon 2002; Thomson et al. 1999). Metalloproteases, which also play an important role in virulence, are secreted through a type I secretion system (Marits et al. 1999, 2002). The soft rot pathogens require other virulence proteins as well for the purposes of iron acquisition (Expert 1999) and efflux pumping (Barabote et al. 2003; Valecillos et al. 2006) and to detoxify antimicrobial peptides (Lopez-Solanilla et al. 1998). Although this class of pathogens possess a T3SS analogous to that of Pseudomonas spp. (Chatterjee et al. 2002), the contribution of the Pectobacterium T3SS to pathogenesis is not fully understood.

To define the role of the T3SS in plant-necrotrophic bacterial pathogen interactions, we used a combination of macroscopic phenotyping, cytological examination of PAMP-induced callose formation, and global-gene expression profiling in the experimental host plant Nicotiana benthamiana. The Solanaceae family, which includes $N$. benthamiana, also includes economically important crops such as tomato, potato, tobacco, and pepper. $N$. benthamiana is used as an experimental model host in the study of a wide range of plant pathogens because of the ease of gene silencing and transient protein expression sys- tems in plant cells using virus-induced gene silencing and because $N$. benthamiana expressed sequence tags (EST) are highly similar to those of important solanaceous crops (Robertson 2004; Wydro et al. 2006). N. benthamiana is susceptible to soft rot pathogens; as little as $10^{2} \mathrm{CFU}$ inoculated into a wounded petiole of $P$. carotovorum (unpublished observations) or the related Dickeya dadantii is sufficient to cause disease (C. E. Jahn, unpublished data). Therefore, the elucidation of host responses in $N$. benthamiana may have broad practical implications for the development of resistant crops.

Pectobacterium spp. infect many leafy hosts, such as lettuce, tobacco, and numerous ornamental plants (Ma et al. 2007). No gene-for-gene resistance has been described for Pectobacterium spp. and no resistance genes of any type have been cloned. As described below, we found that the presence of a functional T3SS was required for disease development in inoculated plant leaves, which has led us to hypothesize that elicitation of plant cell death by the T3SS promotes Pectobacterium spp. pathogenesis on leaves and that acquisition of a T3SS by a Pectobacterium sp. increases the number of tissues it can infect. We also found that the transcriptome expression profiles of $N$. benthamiana in response to the necrotrophic bacterial pathogen $P$. carotovorum WPP14 was similar to that of the response to the hemibiotrophic Pseudomonas syringae pv. tomato DC3000 with a mutated nonfunctional T3SS.

\section{RESULTS}

$D s p E F$ is required for the T3SS-dependent plant cell death caused by Pectobacterium carotovorum in $N$. benthamiana.

Pectobacterium carotovorum WPP14 encodes a functional T3SS but, based on our genetic and sequence analysis, the number of putative T3 candidate effector homologs is likely to be far fewer than in hemibiotrophic phytopathogens, such as Pseudomonas syringae (Glasner et al. 2008; Kim et al. 2009) (B. Mole, personnel communication). Our analysis of genome sequences in the ASAP database (Glasner et al. 2006) shows that DspE is the only effector homolog found in Pectobacterium spp. and in the related soft rot pathogen Dickeya spp.

To examine the response of $N$. benthamiana to proteins secreted via the $P$. carotovorum T3SS, we constructed strains with mutations in T3SS regulatory $(h r p L)$ and structural $(h r c C)$ genes, as well as in genes encoding proteins secreted via the

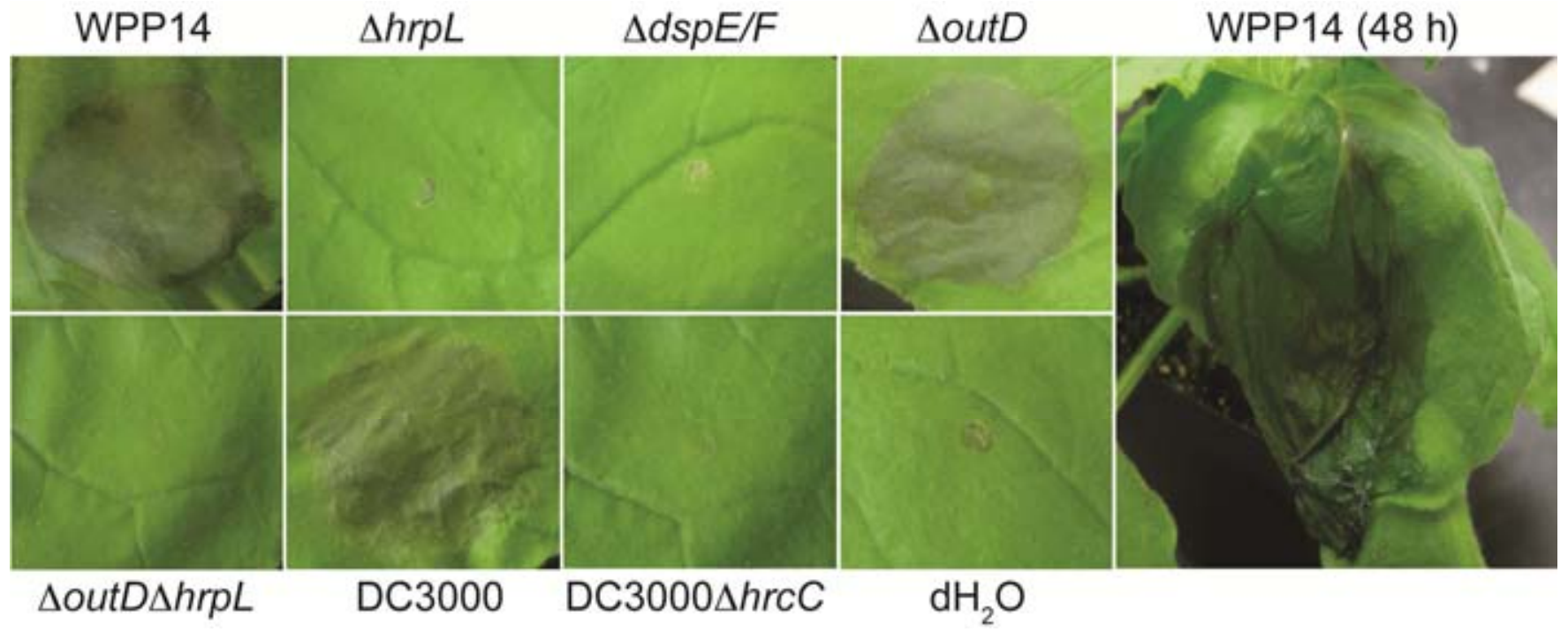

Fig. 1. Type III secretion system (T3SS) and $d s p E / F$ of Pectobacterium carotovorum was required for plant cell death within 24 h after leaf infiltration with $10^{8} \mathrm{CFU} / \mathrm{ml}$ (eight smaller panels). Maceration symptoms developed within $48 \mathrm{~h}$ postinoculationwith wild-type $P$. carotovorum. 
T3SS (dspEF, hrpW, and $h r p N$ ). When infiltrated into Solanum tuberosum (potato) or $N$. benthamiana leaves, we observed that wild-type $P$. carotovorum WPP14 and the hrpN and hrpW mutant strains were able to elicit plant cell death (not shown). In contrast, the $P$. carotovorum $\Delta$ hrpL:gfp:cm, hrcC::sp, and $\triangle d s p E F: s p$ mutants did not elicit plant cell death in either potato (not shown) or N. Benthamiana (Fig. 1). Thus, a functional T3SS and DspE or DspF, but not HrpW or HrpN, are required for T3SS-dependent plant cell death in N. benthamiana. Previous studies have shown that $h r p K$, a putative translocation helper (Petnicki-Ocwieja et al. 2005), is not required for elicitation of plant cell death in $N$. tabacum (Glasner et al. 2008), and we saw the same result with $N$. benthamiana (not shown). Thus, as expected, HrpK does not appear to be required for translocation of DspE or plant cell death.

Unexpectedly, the leaf tissue surrounding the area infiltrated with $P$. carotovorum wild-type, $h r p N$, $h r p K$, or $h r p W$ mutant strains became macerated within $48 \mathrm{~h}$ postinoculation (hpi) (Fig. 1, inoculation with the wild-type strain). By contrast, maceration symptoms did not occur in leaves infiltrated with the $\Delta h r p L, \Delta h r c C$, or $\Delta d s p E F$ deletion mutants under these assay conditions. Our attempts to clone and express the fulllength $d s p E F$ operon were unsuccessful and, therefore, we were unable to complement the mutant phenotype. An independent mutant that had $h r p W, d s p E$, and $d s p F$ deleted was also unable to elicit plant cell death (not shown). When WPP14 hrpL, $h r c C$, and $d s p E F$ mutants were infiltrated into $N$. benthamiana leaves in patches that overlapped regions infiltrated with Pseudomonas syringae DC3000, maceration symptoms developed in the region where both bacteria were infiltrated (data not shown). Pseudomonas syringae DC3000 causes an HR in $N$. benthamiana due to the presence of the T3SS-secreted effector HopQ1-1 (Wei et al. 2007). These results support our hypothesis that elicitation of HR-like plant cell death contributes to Pectobacterium carotovorum virulence in $N$. benthamiana leaves.
An insertion mutation of outD, which is a gene required for a functional T2SS and secretion of plant cell-wall-degrading enzymes, abolished tissue maceration, though the mutant was still able to elicit an HR-like plant cell death (Fig. 1). Thus, the plant cell death elicited by $P$. carotovorum when infiltrated into plant leaves is dependent only upon the T3SS and not the T2SS.

We were unable to detect a growth defect of the $P$. carotovorum T3SS or T2SS mutants in $N$. benthamiana leaves. A chloramphenicol-resistant green fluorescent protein (GFP)labeled derivative of $P$. carotovorum (WPP359) grew approximately $1.5 \log _{10}$ in the first $6 \mathrm{~h}$ after infiltration and $2.5 \log _{10}$ over the course of 3 days when infiltrated at a low level $\left(10^{4}\right.$ $\mathrm{CFU} / \mathrm{ml}$ ) into $N$. benthamiana leaves. The growth of $h r p L$, outD, and $d s p E / F$ mutants in $N$. benthamiana leaves was not significantly different from WPP359 (not shown). Similarly, WPP359 grew an average of 2.5 or $1.6 \log _{10}$ within the first $24 \mathrm{~h}$ after infiltration of $10^{4}$ or $10^{6} \mathrm{CFU} / \mathrm{ml}$ into potato leaves, respectively. The growth of the $d s p E / F$ mutant was not significantly different from that of the wild type in potato leaves (not shown).

Sequenced strains of $P$. atrosepticum (SCRI 1043), P. carotovorum subsp. brasiliensis (1692), and D. dadantii (3937) that encode $d s p E F$ were tested for their ability to elicit plant cell death in $N$. benthamiana. Of these strains, only $P$. carotovorum subsp. brasiliensis 1692 was able to elicit plant cell death in $N$. benthamiana (not shown). Because P. atrosepticum SCRI 1043 and $D$. dadantii 3937 encode functional T3SS and DspE homologs but are unable to elicit the leaf cell death in $N$. benthamiana, this suggests that either the T3SS are not expressed or that allelic differences render these T3SS or the $d s p E$ orthologs nonfunctional or unable to interact with their targets in N. benthamiana.

\section{$P$. carotovorum WPP14 is unable} to impede PAMP-induced callose deposition.

The AvrE from Pseudomonas syringae pv. tomato, DspE/A from E. amylovora (DspE/A $\mathrm{A}_{\mathrm{Eam}}$ ), and WtsE from Pantoea
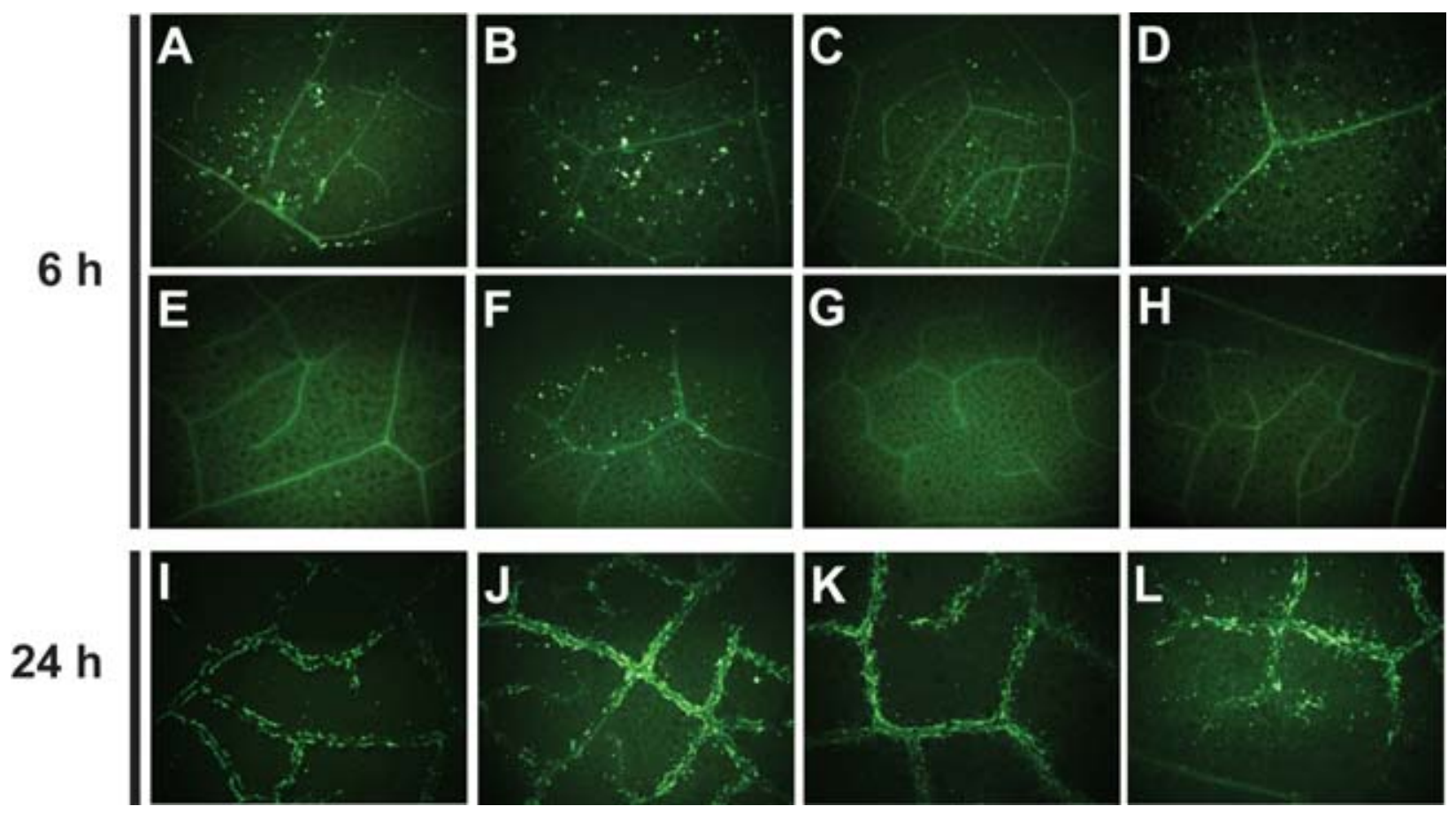

Fig. 2. Pectobacterium carotovorum type III secretion system (T3SS) did not suppress callose deposition, unlike Pseudomonas syringae pv. tomato DC3000, which inhibited pathogen-associated molecular patterns (PAMP)-induced callose deposition. Nicotiana benthamiana leaves were infiltrated with bacteria at $10^{8} \mathrm{CFU} / \mathrm{ml}$ and the leaves were stained with aniline blue to detect callose. Micrographs of callose deposition shown are from one of three independent

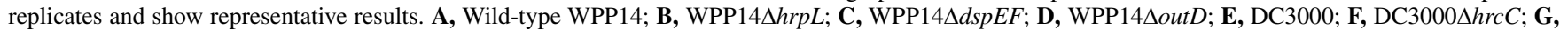

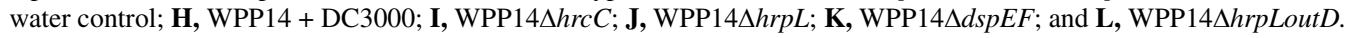


stewartii subsp. stewartii can inhibit callose deposition in plant leaves (DebRoy et al. 2004; Ham et al. 2008, 2009). We hypothesized that the Pectobacterium carotovorum WPP14, which encodes DspE, would also impede PAMP-induced callose deposition. We infiltrated wild-type $P$. carotovorum and $\Delta h r p L, \Delta d s p E / F, \Delta o u t D$, and $\Delta o u t D \Delta h r p L$ deletion mutants into $N$. benthamiana leaves and observed localized callose deposition in the plant cell wall by staining leaf sections with aniline blue at 6 and 24 hpi (Fig. 2). Pseudomonas syringae pv. tomato DC3000 and its $h r c C$ mutant were used as controls (Fig. 2F and $\mathrm{G})$. None of the Pectobacterium carotovorum strains was able to impede callose deposition in N. benthamiana leaves (Fig. 2A to E). As previously reported, Pseudomonas syringae pv. tomato DC3000 was able to suppress callose deposition, which required a functional T3SS. We found that DC3000 could suppress callose deposition normally induced by Pectobacterium carotovorum when Pseudomonas syringae pv. tomato DC3000 was co-infiltrated with Pectobacterium carotovorum strains (Fig.
2H). Therefore, although the Pseudomonas syringae pv. tomato DC3000 AvrE suppresses callose formation, its Pectobacterium carotovorum ortholog, DspE, does not.

\section{P. carotovorum WPP14 induces callose deposition along the veins.}

We examined callose deposition 24 hpi in $N$. benthamiana leaves. To do this, we lowered the initial concentration of WPP14 to $10^{7} \mathrm{CFU} / \mathrm{ml}$ in order to delay plant cell death and maceration symptoms. P. carotovorum WPP14 induced strong callose deposition along the plant veins within 24 hpi (Fig. 3A). This callose deposition did not require either the T3SS or T2SS (Fig. 2J to L). We did not observe callose deposition along the vascular system in plants inoculated with Pseudomonas syringae. This finding prompted us to suspect that the Pectobacterium carotovorum cells were either moving in the leaves toward the leaf vascular system or mainly growing along or inside of the vascular system. Alternatively, a diffusible signal could be
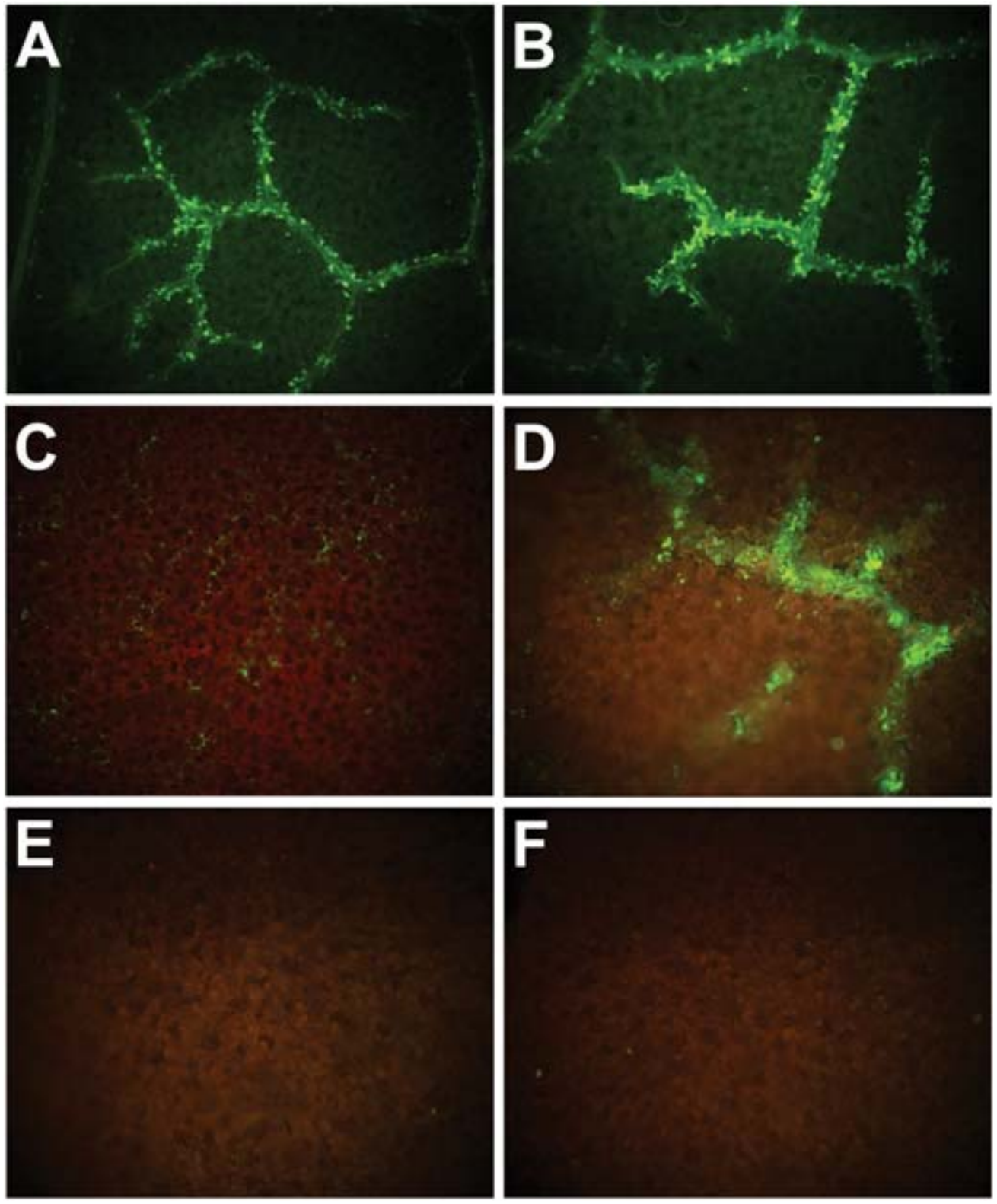

Fig. 3. Bacterial localization along the vein triggered strong callose deposition on Nicotiana benthamiana within $24 \mathrm{~h}$ after bacterial infiltration. Callose deposition stained with aniline blue $24 \mathrm{~h}$ after infiltration with A, WPP14 or B, WPP14(p519nGFP) at 108 CFU/ml. C, A green fluorescent protein (GFP) fluorescence image was taken at $0 \mathrm{~h}$ after infiltration with WPP14(p519nGFP) (optical density at $600 \mathrm{~nm}\left[\mathrm{OD}_{600}=1.0\right]$ ). GFP fluorescence images were obtained at $24 \mathrm{~h}$ after the infiltration of D, WPP14(p519GFP); E, WPP14; or F, $\mathrm{dH}_{2} \mathrm{O}$. 
eliciting callose deposition along the veins. To test this, we transformed WPP14 with p519nGFP in order to visualize WPP14 cells in leaves. WPP14(p519nGFP) also induced the same strong callose formation along the plant veins as WPP14 (Fig. 3A and B). Within 24 hpi with WPP14(p519nGFP), we observed localized bacterial cells along the plant veins, indicating that the $P$. carotovorum cells were co-localized with the leaf vein callose (Fig. 3D). This finding supported the hypothesis that $P$. carotovorum cells along the vasculature elicit a defense response.

Sequence comparison of AvrE family effectors from necrotrophic and hemibiotrophic pathogens.

Deletion studies have demonstrated that amino acid residues 237 to 492 of Pantoea stewartii subsp. stewartii WtsE are essential for virulence and induction of plant cell death (Ham et al. 2008). Like WtsE, AvrE proteins from both Pseudomonas syringae and E. amylovora have a long, variable N-terminal extension. However, it is absent from the DspE orthologs of Pectobacterium carotovorum and the related necrotrophs $P$. atrosepticum and D. dadantii (Fig. 4A). AvrE/DspE/WtsE proteins from the hemibiotrophic pathogens possess one or two W/YXXXE/D motifs (Ham et al. 2009) and deletion of these motifs eliminates plant cell death and callose suppression activity of WtsE. This motif is also commonly found in animal pathogen $\mathrm{T} 3$ effectors, and these W/YXXXE/D-containing effectors are thought to mimic host guanosine triphosphateactivated small G proteins (Alto 2008; Alto et al. 2006). A putative C-terminal endoplasmic reticulum membrane retention signal (LKKEG[F/L]E[L/M]KS) has also been shown to

\title{
A
}

141 SPGVSRHSVEDMRDKPVAKADPRE..TSAIDIKHQLNNFNQMRQNILNKTRPFSQGATTSSVMDARAPLP $P$. steWartii 133 SGGVKRRNMDDMAGRPMVKGGSGEDKVPTQQKRHQLNNFGQMRQTMLSKMAHPASANAGDRLQHSPPHIP

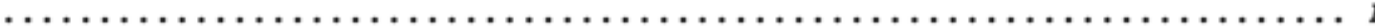

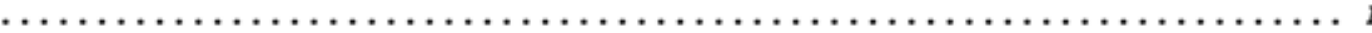

261 LPAIAENTAEAEANRRIQPLQTPPPLEN. . TPVSPLSLTLDKG 273 TAVAESVLEGTDTT QSPLKPOSMLKGSGAGVTPLAVTLDKGKRLDSNPT PMNTLLEQTLGKEGCHY

GKLQLAPDNPPALNTLLKOTLGKDTCHY

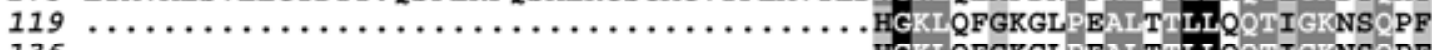

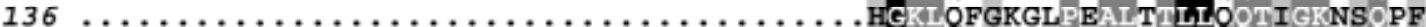

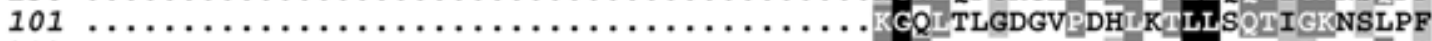

213 SDGPIPPREPMLWRSNGGRFELKDEKLVRNSEPQGSIQLDAKG PDFSTFNTPGIAPLLDSILATPKOTY

\author{
. amylovora \\ atrosepticum \\ carotovorum \\ dadantii \\ syringae
}

B

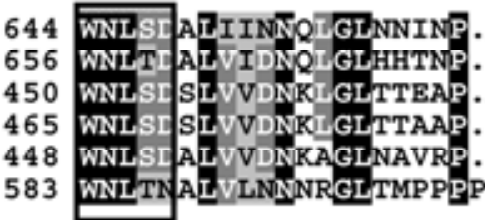

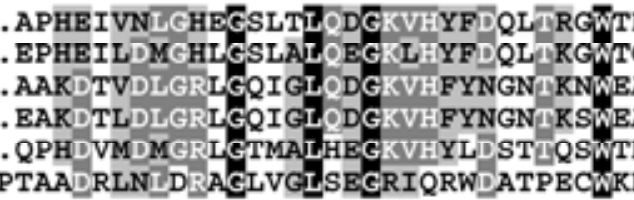

TEA. EAGCQQLKKGLDGG $P$. TGA. ESDCKOLKKGLDGA $E$. stewartii amylovora atrosepticum carotovorum dadantii syringae

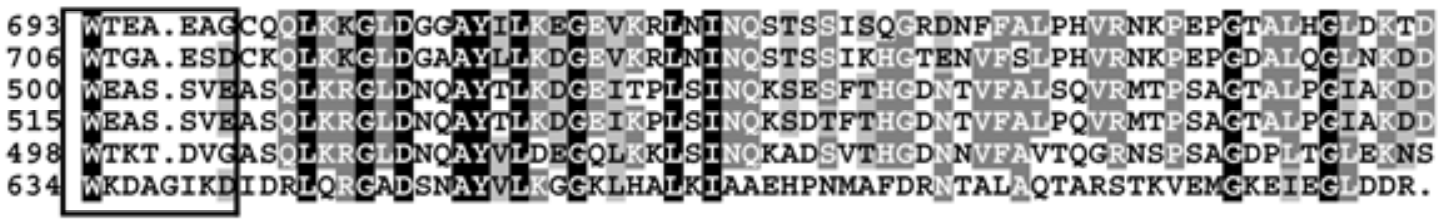
AS. SVEASQLKRGLDNQ $P$. KT. DVGASOLKRGLDNQ D.

stewartii amylovora atrosepticum carotovorum dadantii syringae

839 WQQ...GESGRGWRLTMPPGESGIDRIETDAHFHPVAVLLDGSRYQIRGETTHPQNASEPTQIETGLRD P. stewartii

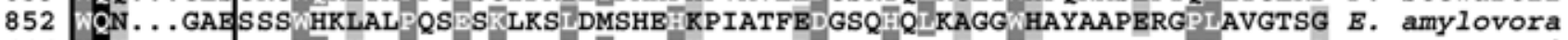

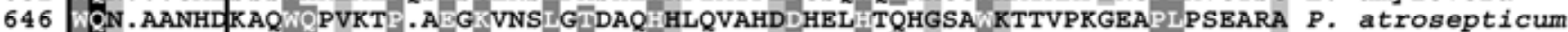

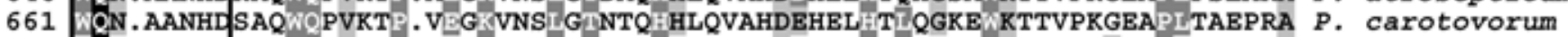
644 LQGNAEARANAQWOPVTLP. DNV PEHLSTTKNIEPAISEDGHQQHQLTQSGKSAVP. DTQPNHPQPRA D. dadanti 773 QSTKLGD Q LRARWTPVALPGGQPVKALFLNDDNVLSAQIBDABGKGLMQLKAGQWQRFEQRPVE.. ENG P. sYringae C
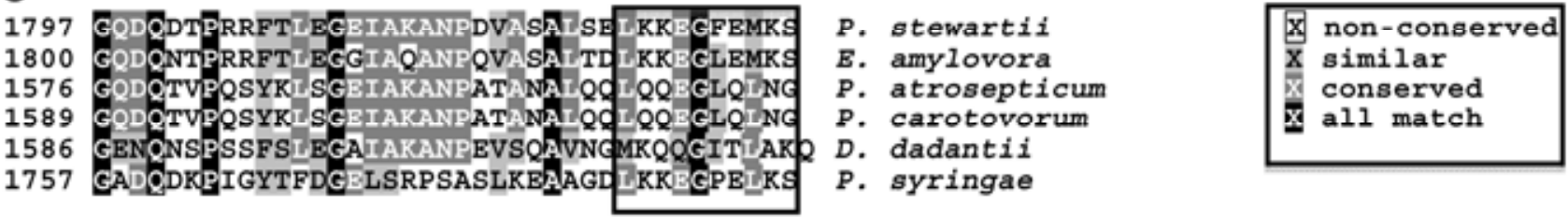

Fig. 4. Multiple sequence alignment with hierarchical clustering of DspE homologs in plant-pathogenic bacteria: Pantoea stewartii subsp. stewartii WtsE (AAG01467.2), Erwinia amylovora DspE (AAC04850.1), Pectobacterium atrosepticum DspE (AAS20351.1), P. carotovorum DspE (ASAP ID ADT0003862), Dickeya dadantii DspE (YP_003883118.1), and Pseudomonas syringae pv. tomato AvrE (AAF71499). Numbers on the left indicate amino-acid positions. Motifs similar to WXXXE/D and LKKEG[F/L]E[L/M]KS are boxed. 
be important for virulence function and HR elicitation by WtsE of Pantoea stewartii subsp. stewartii (Ham et al. 2009). Ham and associates reported that Pectobacterium atrosepticum lacks both motifs. Our searches of the entire predicted $P$. carotovorum and Dickeya spp. DspE sequences found that none of the alleles from these necrotrophic pathogens contain WXXXE or the endoplasmic reticulum membrane retention signal; however, WXXXD can be found as well as WXXXXXE and WXXXXXXD in regions that align to the WXXXE motif in Pantoea stewartii (Fig. 4B and C).

\section{The MAPK signaling cascade is not activated}

\section{by the Pectobacterium carotovorum WPP14 T3SS.}

Activation of MAPK genes, an early step in the signal transduction pathway initiated by PAMPs, can be intercepted by some Pseudomonas syringae pv. tomato DC3000 T3 effectors such as AvrPto, AvrPtoB, and HopAI1 (He et al. 2006; Zhang et al. 2007). To investigate the possible role of the Pectobacterium T3SS in activation of the MAPK signaling pathway, we used quantitative polymerase chain reaction (qPCR) to examine the relative transcriptional levels of $N b M A P K K K \alpha$ (del Pozo et al. 2004) and NbMEK2 (Asai et al. 2008) in N. benthamiana induced by Pectobacterium carotovorum WPP14, WPP14thrpL, Pseudomonas syringae pv. tomato DC3000, and Pseudomonas syringae pv. tomato DC3000 $\Delta$ hrcC. Our qPCR results demonstrated that neither $N b M A P K K K \alpha$ nor NbMEK2 transcription was activated by the Pectobacterium
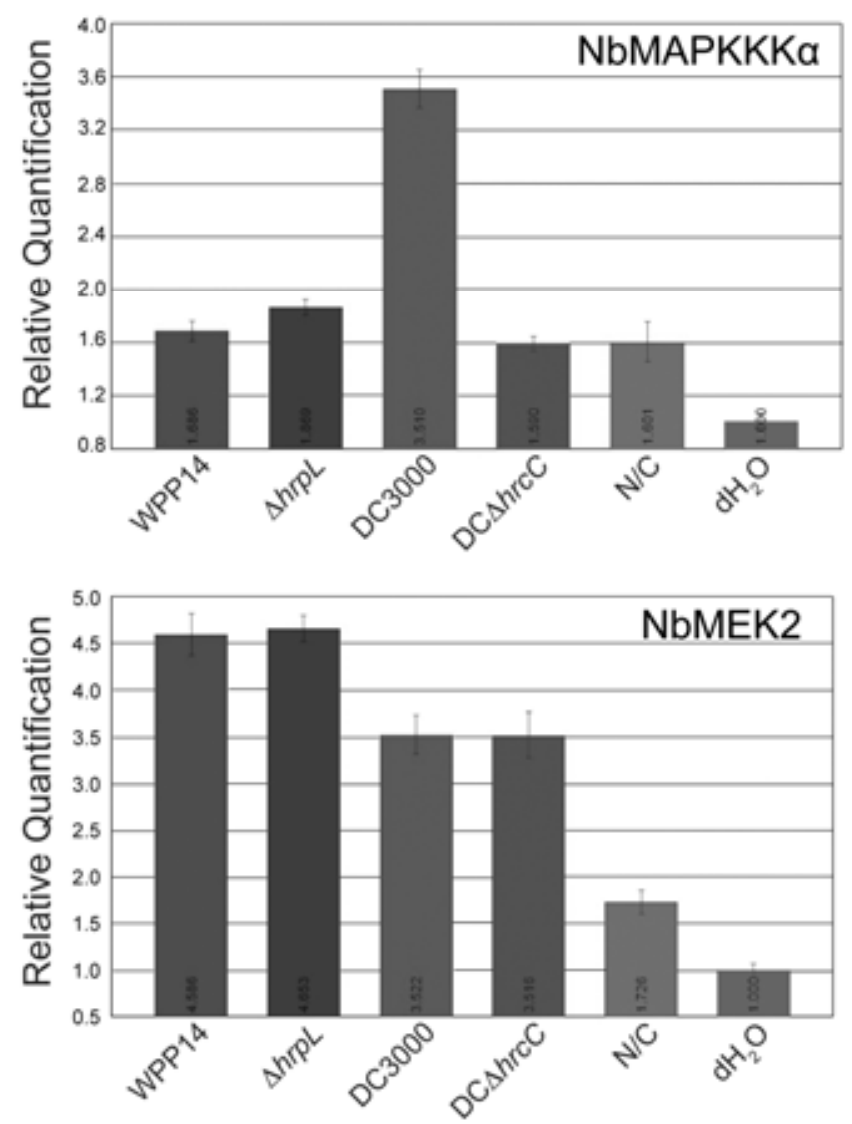

Fig. 5. Quantitative polymerase chain reaction (qPCR) analysis of the genes involved in mitogen-activated protein kinase (MAPK) signaling pathway to determine the relative expression levels of $N b M A P K K K \alpha$ and NbMEK2 in Nicotiana benthamiana in response to WPP14, $\Delta$ hrpL, Pseudomonas syringae pv. tomato DC3000, or Pseudomonas syringae pv. tomato DC3000 4 hrc . Water-infiltrated and untreated leaves $\left(\mathrm{dH}_{2} \mathrm{O}\right.$ and N/C) were used as negative controls. Total RNAs from $N$. benthamiana leaves were isolated at $3 \mathrm{~h}$ postinoculation. carotovorum T3SS (Fig. 5). The expression level of NbMAPKKK $\alpha$ was significantly upregulated (1.25-fold) only when leaves were infiltrated with Pseudomonas syringae pv. tomato DC3000 (Fig. 5). We found that NbMEK2 was slightly but significantly upregulated in WPP14 and $\Delta h r p L(0.25$-fold $)$ compared with in DC300 and DC30004hrcC.

\section{Transcriptome profiling of $N$. benthamiana in response to Pectobacterium carotovorum WPP14.}

Our qPCR and callose data suggest that Pectobacterium carotovorum does not suppress $N$. benthamiana defense responses. To further examine this, we used microarrays to measure the expression of $N$. benthamiana genes in response to $P$. carotovorum WPP14 and compared it with responses elicited by Pseudomonas syringae pv. tomato DC3000. We chose to examine plant gene expression at 3 hpi because WPP14 $d s p E$ expression occurs within $1 \mathrm{hpi}$ in leaves (B. Mole, personal communication) and because we could no longer inhibit plant cell death with tetracycline at $3 \mathrm{hpi}$. We isolated transcripts at 3 hpi from leaves infiltrated with $\mathrm{dH}_{2} \mathrm{O}$, WPP14, $\Delta h r p L$, $\Delta d s p E / F, \mathrm{DC} 3000$, and the DC3000 hrcC mutant. Untreated leaves were also used as a control. The transcripts were labeled with either $\mathrm{Cy} 3$ or $\mathrm{Cy} 5$ fluorophores and were hybridized to a microarray designed from the $N$. benthamiana transcriptome.

For visualization of multivariate data, we used principal component analysis (PCA), which reduces the high dimensionality of a dataset to capture the principal variations (components) in gene expression values (Ringnér 2008). Based on PCA mapping, the biological replicates and Cy3 to Cy5 fluorophore labeling method were not different from each other (not shown). In contrast, samples inoculated with DC3000 were clearly distinct from samples inoculated with the Pectobacterium carotovorum strains and Pseudomonas syringae pv. tomato DC3000 $\Delta$ hrc C (not shown).

Volcano plots were used to represent the global gene-expression patterns upon the different bacterial infection by comparing the estimated $\log _{2}$ fold change ( $x$ axis) against its statistical significance, which is calculated by mixed model analysis of variance (ANOVA) ( $y$ axis) (Fig. 6). Large changes in the transcriptome of $N$. benthamiana were observed when samples infiltrated with WPP14 or DC3000 $h r c C$ were compared with wild-type DC3000 (Fig. 6A and B). There was little difference in $N$. benthamiana gene expression profiles to infiltration with Pectobacterium carotovorum WPP14 or Pseudomonas syringae pv. tomato DC3000 $4 \mathrm{rcC}$ (Fig. 6C), suggesting that the initial response of $N$. benthamiana to the necrotrophic Pectobacterium carotovorum WPP14 is similar to the response to a Pseudomonas syringae T3SS mutant. We investigated changes in the transcriptome of $N$. benthamiana induced by the Pectobacterium T3SS by comparing plants infiltrated with wild-type WPP14 to those infiltrated with WPP14 hrpL or WPP14 $d s p E / \mathrm{F}$ mutant strains. We could not detect significant differences in $N$. benthamiana gene expression in response to either the Pectobacterium T3SS or the T3 effector, DspE (Fig. 6D and $\mathrm{E})$.

By using a $P$ value criterion from ANOVA results to declare differentially expressed genes (DEG), the false-positive rate (type I errors) was controlled by performing false discovery rate (FDR) analysis at $P$ values of 0.05 and 0.01 (Table 1; Supplementary Table 1 ). At a rate of 0.05 , changes in transcription levels in response to bacterial infiltration were statistically similar for all Pectobacterium strains tested. Among the 1,666 DEG in the comparison between Pseudomonas syringae pv. tomato DC3000 and WPP14, 734 and 932 genes were up- or downregulated, respectively (Table 1 ). In contrast, we identified only 13 DEG when we compared infection with DC3000 $4 h r c C$ to WPP14, indicating that the gene expression on $N$. bentha- 
miana following WPP14 infection is similar to that of the Pseudomonas syringae pv. tomato DC3000 T3SS mutant (Table 1). Subsequently, we compared the DEG among samples, and found that the DEG sets of DC3000 versus WPP14 overlapped almost entirely with that of DC3000 versus DC3000 $\operatorname{hrcC}$ (347 of 361; 96\%). Consistent with our qPCR results, the average expression level of the two NbMAPKKK on the microarray in response to DC3000 was higher than in response to WPP14 or DC $3000 \Delta h r c C$. NbMAPKKK $\alpha$ (del Pozo et al. 2004) was upregulated in leaves infiltrated with DC3000 1.8 -fold $(P=1.5 \mathrm{e}-005)$ and 2.0 -fold $(P=5.2 \mathrm{e}-005)$ compared with leaves inoculated with WPP14 and DC3000 $\Delta h r c C$, respectively. Only one of these genes, NbMAPKKK, was induced when gene expression was compared between leaves infiltrated with WPP14 and with water (fold change 9.79824, $P$ value $4.8 \times 10^{-6}$ ). Probes for $N b M E K 2$, the other gene assayed with qPCR, were not on the microarray. WPP14 altered gene expression compared with water-inoculated controls and caused induction of 2,030 genes and repression of 439 genes.

\section{DISCUSSION}

We found that the T3 effector, DspE/F, is required for plant cell death when Pectobacterium carotovorum WPP14 is inoculated at high levels into $N$. benthamiana leaves. Deletion of $d s p E / F$ eliminates the T3SS-dependent leaf cell death caused by $P$. carotovorum and subsequent maceration symptoms. $\mathrm{DspE} / \mathrm{F}$ is also required for $P$. carotovorum to cause leaf cell death in $S$. tuberosum (cultivated potato) and most of the 156 accession of wild potato species from over 30 different So- lanum spp. tested when the bacteria were inoculated at high levels $\left(10^{8} \mathrm{CFU} / \mathrm{ml}\right)$ (unpublished results). Although $P$. carotovorum causes a T3SS-dependent plant cell death, we saw no changes in plant gene regulation dependent upon a functional T3SS early in the plant-bacteria interaction. In contrast, 361 $N$. benthamiana genes were differentially regulated in response to the Pseudomonas syringae pv. tomato DC3000 T3SS under the same conditions. Also, unlike with DC3000, we found no indication that Pectobacterium carotovorum suppresses callose formation in leaves. This may be due to the lack of the variable $\mathrm{N}$-terminal region or the putative endoplasmic reticulum membrane retention signal in the $P$. carotovorum DspE allele (Ham et al. 2009). Together with data from other labs discussed below, our results support the hypothesis that DspE aids $P$. carotovorum in attacking leaf tissue by causing plant cell death rather than by suppressing plant defenses.

Gene-for-gene resistance has not been reported for necrotrophic bacterial pathogens, and host cell death is not expected to restrict necrotrophic pathogen growth (Glazebrook 2005). For instance, a necrotrophic fungal pathogen, Botrytis cinerea, has been proposed to induce plant cell death as an important part of its pathogenesis (Govrin and Levine 2000). Govrin and Levine (2000) found that co-inoculation with B. cinerea and Pseudomonas syringae strains able to induce an HR promoted virulence of $B$. cinerea. Similarly, Pectobacterium carotovorum is unable to infect Arabidopsis "death no defense" mutants (Ahn 2007), suggesting that elicitation of leaf cell death promotes $P$. carotovorum virulence.

Although the T3SS-dependent cell death caused by $P$. carotovorum in $N$. benthamiana leaves appears to be similar to the
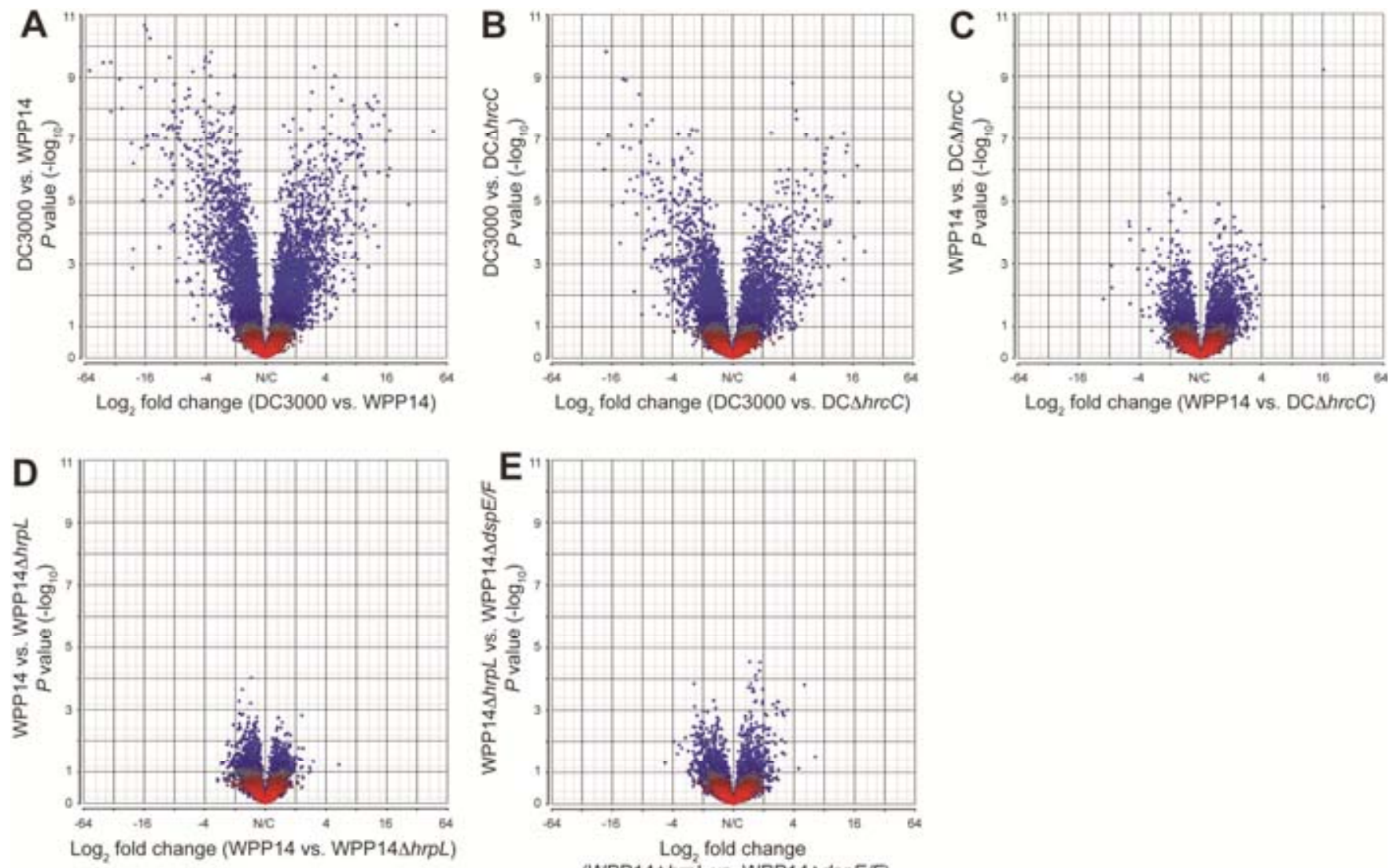

(WPP14AhrpL vs. WPP14AdspE/F)

Fig. 6. Volcano plots depicting fold change ( $\log _{2}, x$ axis) and statistical significance ( $\log _{10} P$ value from analysis of variance [ANOVA], $y$ axis). Each circle represents a Nicotiana benthamiana gene. $P$ values were calculated from multiple ANOVA handling three categorical factors, including Cy3-Cy5 fluorophore labeling, biological independent replicates, and five bacterial treatments and the interaction with fluorophore labeling and bacterial treatments comparing the transcriptional profiles induced by A, DC3000 compared with WPP14; B, DC3000 compared with DC3000 $\Delta h r c$; C, WPP14 compared with DC $\Delta h r c C$; D, WPP14 compared with WPP14 $h r p L$; and E, WPP14 compared with WPP14 $\Delta d s p E / F$. N/C means no change. 
plant cell death caused by Pseudomonas syringae pv. tomato DC3000, we do not know if it is an active response of the plant (an HR) due to direct toxicity of the DspE protein or because DspE function allows another bacterial protein to cause plant cell death. Ham and associates (2008) found that the Pantoea stewartii subsp. stewartii DspE homolog WtsE can cause cell death in yeast (Saccharomyces cerevisiae) and other Pseudomonas syringae pv. tomato DC3000 effectors are toxic when expressed in eukaryotic cells (Munkvold et al. 2008), suggesting that the cell death observed may be caused directly by DspE. However, the plant signaling protein SGT1 is required for leaf cell death when $N$. benthamiana is infiltrated with either Pseudomonas syringae or Pectobacterium carotovorum; thus, DspE function appears to be tied to the SGT1 pathway (Wang et al. 2010). Because SGT1 is required for R-proteinmediated plant cell death in many plant species, this suggests that $P$. carotovorum DspE elicits plant cell death via R-proteinmediated recognition. Because DspE toxicity and R-proteinmediated plant cell death are not mutually exclusive, and one or the other could be operating in different plant species or genotypes, the role of DspE in disease should be examined in multiple plant species.

Previously, Holeva and associates (2004) reported that mutation of DspE in $P$. atrosepticum caused a small reduction in bacterial virulence in potato stems, and others found that in $E$. amylovora DspE contributes to bacterial growth in apple and $N$. benthamiana leaves and in pear fruit (Bogdanove et al. 1998a; Gaudriault et al. 1997; Oh et al. 2007). We have been unable to detect a significant role for the $P$. carotovorum T3SS in bacterial growth in $S$. tuberosum tubers, stems, or leaves or $N$. benthamiana leaves inoculated with concentrations ranging from $10^{4}$ to $10^{7} \mathrm{CFU} / \mathrm{ml}$ (unpublished observations). Similarly, Wang and associates (2010) were unable to detect any difference in $P$. carotovorum growth between $N$. benthamiana wildtype or SGT1-silenced plants. Thus, in $N$. benthamiana leaves, neither the $P$. carotovorum T3SS nor SGT1-mediated cell death appears to affect $P$. carotovorum growth. DspE/F does contribute to pathogenesis when leaves are inoculated at high levels because the T3SS and DspE/F were required for subsequent plant maceration. High levels of $P$. carotovorum inoculum often occur in agricultural settings, with dramatic storage decays being the most well-known example. In addition, in fields, potato vines are typically 6 feet or more in length and, in late summer, will lie in a tangled mass in the field. If $P$. $c a-$ rotovorum stem rot has occurred, macerated vines will lie across healthy plants and high levels of bacteria may ooze onto healthy vines and leaves, spreading disease. $P$. carotovorum wild-type WPP14 and T3SS mutants cause potato and N. benthamiana plants to wilt when the bacteria are inoculated directly into the vascular tissue by placing droplets of inoculum onto cut petioles (unpublished observations). We have not yet resolved the contradiction between the reduction in virulence on leaves observed with $P$. carotovorum T3SS mutants and the lack of a virulence reduction phenotype when the same T3SS mutants are inoculated into plant stems.

A similar role in plant cell death but not bacterial growth was previously seen with the GacAS two-component system in
Pseudomonas syringae. A gacA (lemA) mutant is unable to form lesions on leaves but grows as well as the wild type in growth-chamber plant assays (Willis et al. 1990). Extensive field assays demonstrated that lesions are likely required for survival when leaves are dry (Hirano et al. 1997), suggesting an essential role for GacAS in disease, even though it does not contribute to bacterial growth in laboratory assays. Additional work will be required to determine the role of $\mathrm{DspE}$ under field conditions and to resolve the cell-killing phenotype we observe with the apparent lack of significant contribution to bacterial growth in plants.

To attempt to identify the role of DspE in Pectobacterium carotovorum pathogenesis, we decided to determine whether $N$. benthamiana gene expression is altered in a T3SS-dependent manner during initial interactions with $P$. carotovorum. We first used quantitative reverse-transcription (qRT)-PCR to examine a MAPK cascade that is induced when Pseudomonas syringae pv. tomato DC3000 elicits an HR in N. benthamiana, then later looked at expression of these genes with microarrays. Previously, Pseudomonas syringae pv. tomato AvrPto and AvrPtoB were shown to repress MAPK expression in Arabidopsis (He et al. 2006). We saw the opposite effect in the nonhost plant $N$. benthamiana, where DC3000 activates this cascade in a T3SS-dependent fashion. Unlike DC3000, the Pectobacterium carotovorum T3SS does not affect expression of genes in this cascade. It is possible that $N b M A P K K K \alpha$ activation by the Pseudomonas syringae pv. tomato DC3000 T3SS is required for plant cell death during the $N$. benthamiana defense response because $N b M A P K K K \alpha$ was reported to be a convergent point for $R$-gene-mediated cell death signaling (del Pozo et al. 2004).

To explore the $N$. benthamiana response to Pectobacterium carotovorum, we determined whether there were global changes in $N$. benthamiana gene expression caused by the interaction with $P$. carotovorum wild-type WPP14 and the $\Delta h r p L$ and $\Delta d s p E / F$ mutants and compared these with global changes caused by Pseudomonas syringae pv. tomato DC3000 wild-type and $\Delta h r c C$ mutant strains. We found that $361 \mathrm{~N}$. benthamiana genes responded to the presence of a functional DC3000 T3SS. In contrast, the $N$. benthamiana response to Pectobacterium carotovorum was almost identical to the plant response to a Pseudomonas syringae pv. tomato DC3000 hrcC mutant. Unlike DC3000, Pectobacterium carotovorum appears to encode only a single effector, DspE, which is one likely reason for the similarity in plant response to $P$. carotovorum and the Pseudomonas syringae pv. tomato DC3000 hrcC mutant. Because this microarray contained probes to detect an estimated $38 \%$ of the transcriptome, it is possible that $N$. benthamiana genes affected by DspE are not represented on this array or that later time points need to be examined.

Only six genes were differentially expressed between plants inoculated with Pectobacterium carotovorum WPP14 and the Pseudomonas syringae pv. tomato DC3000 hrcC mutant, and only one of these has a putative function in plants. This gene, NBENT00S00005865, is a putative WRKY72 ortholog. The tomato WRKY72 is a transcription factor that is involved in

Table 1. Total number of the Nicotiana benthamiana genes significantly differentially expressed using false discovery rate (FDR)

\begin{tabular}{|c|c|c|c|c|}
\hline Variable name & Level of FDR & Number of significant $P$ values & Upregulated & Downregulated \\
\hline DC3000 vs. WPP14 & 0.01 & 1,666 & 734 & 932 \\
\hline DC3000 vs. DC3000 $4 h r c C$ & 0.01 & 361 & 156 & 205 \\
\hline DC3000 $h h r c C$ vs. WPP14 & 0.05 & 13 & 7 & 6 \\
\hline WPP14 vs. WPP14 $h r p L$ & 0.05 & 0 & 0 & 0 \\
\hline WPP14 vs. WPP14 $\Delta d s p E / F$ & 0.05 & 0 & 0 & 0 \\
\hline WPP14 vs. $\mathrm{H}_{2} \mathrm{O}$ & 0.01 & 2,469 & 2,430 & 39 \\
\hline
\end{tabular}


Mi-1-mediated resistance and basal resistance against rootknot nematodes, as well as basal defenses against potato aphids and Pseudomonas syringae (Bhattarai et al. 2010). In Arabidopsis, WRKY72 contributes to basal defense against Hyaloperonospora arabidopsidis and root-knot nematodes but not Pseudomonas syringae (Bhattarai et al. 2010). Basal defenses against Pectobacterium carotovorum do not seem to act via the SA pathway (Vidal et al. 1997) and, interestingly, the WRKY72 regulon in Arabidopsis includes mainly genes that are not responsive to SA analogs (Bhattarai et al. 2010).

Suppression of cell-wall-based extracellular defenses, such as callose deposition, by T3SS effectors is thought to enable plant pathogens to enhance growth (Hauck et al. 2003). For example, growth of a Pseudomonas syringae pv. tomato DC3000 hrcC mutant is inhibited in planta due to the induction of PAMP-induced innate defense (Hauck et al. 2003; Kim et al. 2005). DebRoy and associates (2004) found that AvrE and DspE/A suppress defense-associated callose deposition in the host cell wall. However, our results show that wild-type Pectobacterium carotovorum does not suppress callose deposition; rather, we observed spots of callose formation $6 \mathrm{hpi}$ in leaves and strong callose formation along plant veins $24 \mathrm{hpi}$ with $P$. carotovorum. This phenomenon is independent of the T2SS and T3SS and is concurrent with bacterial growth along or localization to the plant veins. Similar callose deposition was observed in Arabidopsis leaves inoculated with a wild type and T2SS mutant of the closely related soft rot pathogen, D. dadantii (Fagard et al. 2007). It is possible that plant-microbe interactions resulting in induction of callose deposition concurrently downregulate other defense responses. For example, callose-deficient Arabidopsis mutants are resistant to the biotrophic fungal pathogen, Erysiphe cichoracearum, which causes powdery mildew on wild-type Arabidopsis (Jacobs et al. 2003; Nishimura et al. 2003). Moreover, Nishimura and associates revealed that callose deposition antagonizes the SA signaling pathway, a relatively late defense response (Nishimura et al. 2003). To determine whether callose deposition caused by the necrotrophic $P$. carotovorum WPP14 affects virulence, host plants deficient in callose synthesis or $P$. carotovorum transformants capable of suppressing callose will need to be examined.

We hypothesize that, like other necrotrophs, $P$. carotovorum benefits from elicitation of plant cell death and that it uses the T3SS effector protein DspE to kill plant cells, perhaps in the absence of a cognate $\mathrm{R}$ protein, to promote soft rot disease. In soft rot pathogens, the effector protein, DspE, appears to lack motifs conserved among hemibiotrophic pathogens, such as Pseudomonas syringae, and also to lack the ability to suppress callose formation, while the cell-killing activity appears to remain conserved. Hybrid DspE proteins constructed from hemibiotroph and necrotroph alleles may provide insight into the molecular functions of DspE. Our gene-expression assays did not identify putative targets of the Pectobacterium carotovorum T3SS or provide insight into the mechanism by which DspE kills plant cells, but others have shown that $P$. carotovorum requires SGT1 to kill $N$. benthamiana leaf cells, suggesting that DspE acts via the same pathway as typical Avr-R protein interactions. Together, these data suggest that $P$. carotovorum has co-opted the T3SS and a single secreted effector protein to elicit plant cell death in order to promote its necrotrophic lifestyle; however, additional work, ranging from biochemical characterization of DspE to a better understanding of $P$. carotovorum ecology, is required for further support of this model.

Table 2. Bacterial strains and plasmids used in this study

\begin{tabular}{|c|c|c|}
\hline Strains, plasmids & Relevant characteristics & References \\
\hline \multicolumn{3}{|c|}{ Pectobacterium carotovorum } \\
\hline WPP14 & Wild-type strain isolated from an infected potato stem from a Wisconsin field in 2001 & Ma et al. 2007; Yap et al. 2004 \\
\hline WPP77 & $\mathrm{Sp}^{\mathrm{r}} \mathrm{Ap}^{\mathrm{r}}, \Delta h r c C: \because \operatorname{sp}(\mathrm{p} 519 \mathrm{nGFP})$ & This work \\
\hline WPP195 & $\mathrm{Cm}^{\mathrm{r}}, \Delta h r p N: \because g f p-c m$ derivative of WPP14 & This work \\
\hline WPP198 & $\mathrm{Cm}^{\mathrm{r}}, \Delta h r p L:: g f p-\mathrm{cm}$ derivative of WPP14 & This work \\
\hline WPP203 & $\mathrm{Cm}^{\mathrm{r}}, \Delta h r p W:: c m$ derivative of WPP14 & This work \\
\hline WPP284 & $\mathrm{Km}^{\mathrm{r}}, \mathrm{Cm}^{\mathrm{r}}, \Delta$ outD $:: k m \Delta h r p L:: \mathrm{cm}$ derivative of WPP14 & This work \\
\hline WPP359 & $\mathrm{Cm}^{\mathrm{r}}$, gfp :: $\mathrm{cm}$-labeled WPP14 & This work \\
\hline WPP361 & $\mathrm{Cm}^{\mathrm{r}}, \Delta h r p K: \because g f p-c m$ derivative of WPP14 & This work \\
\hline WPP460 & $\mathrm{Km}^{\mathrm{r}}, \Delta$ outD derivative of WPP14 & This work \\
\hline WPP477 & $\mathrm{Sp}^{\mathrm{r}}, \Delta d s p E / F: \because s p$ derivative of WPP14 & This work \\
\hline WPP497 & $\mathrm{Sp}^{\mathrm{r}}, \Delta h r p W \_d s p E / F: \because s p$ derivative of WPP14 & This work \\
\hline WPP14(p519GFP) & $\mathrm{Ap}^{\mathrm{r}}$, WPP14 carrying p $519 \mathrm{nGFP}$ & This work \\
\hline \multicolumn{3}{|c|}{ Pseudomonas syringae pv. tomato } \\
\hline DC3000 & Wild-type strain & \\
\hline DC3000 $\Delta \mathrm{hrcC}$ & $\mathrm{Cm}^{\mathrm{r}}, \Delta h r c C$ derivative of Pseudomonas syringae pv. tomato $\mathrm{DC} 3000$ & Yuan and He 1996 \\
\hline \multirow{2}{*}{\multicolumn{3}{|c|}{ 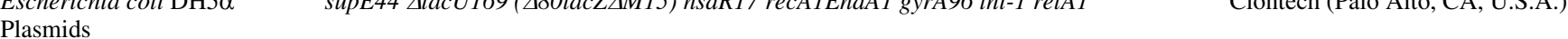 }} \\
\hline & & \\
\hline pBluescript SK(+/-) & $\mathrm{Ap}^{\mathrm{r}}$, lac $Z^{\prime}$, cloning vector & $\begin{array}{l}\text { Agilent Technologies (Santa } \\
\text { Clara, CA, U.S.A.) }\end{array}$ \\
\hline pGEM-T Easy & $\mathrm{Ap}^{\mathrm{r}}$, lac $Z^{\prime}$,cloning vector & Promega \\
\hline pCPP50 & $\mathrm{Ap}^{\mathrm{r}}$, cloning vector & Bogdanove et al. 1998b \\
\hline pTA::gfp-cm & $\begin{array}{l}\mathrm{Ap}^{\mathrm{r}}, \mathrm{Cm}^{\mathrm{r}}, 4.1-\mathrm{kb} \text { fragment containing } \mathrm{Cm}^{\mathrm{r}} \text { from } \mathrm{pKD} 3 \text { and gfp from } \mathrm{p} 519 \mathrm{n} \\
\text { pGEM-T Easy }\end{array}$ & This work \\
\hline pKD3 & $\mathrm{Cm}^{\mathrm{r}}$, template plasmid carrying $\mathrm{Cm}^{\mathrm{r}}$ cassette & Datsenko and Wanner 2000 \\
\hline pKD4 & $\mathrm{Km}^{\mathrm{r}}$, template plasmid carrying $\mathrm{Kan}^{\mathrm{r}}$ cassette. & Datsenko and Wanner 2000 \\
\hline $\mathrm{pHP} 45 \Omega \mathrm{Sp}$ & $\mathrm{Ap}^{\mathrm{r}}, \mathrm{Sp}^{\mathrm{r}} / \mathrm{Sm}^{\mathrm{r}}$, template plasmid carrying $\mathrm{Sp}^{\mathrm{r}}$ cassette & Fellay et al. 1987 \\
\hline pTA $\Delta h r p L \_$AB & $\mathrm{Ap}^{\mathrm{r}}, 2.5-\mathrm{kb}$ upstream region of $h r p L$ in pGEM-T Easy & This work \\
\hline pTA $\Delta h r p L \_C D$ & $\mathrm{Ap}^{\mathrm{r}}, 1.7-\mathrm{kb}$ downstream region of $h r p L$ in pGEM-T Easy & This work \\
\hline $\mathrm{pBS} \Delta h r p L$ & $\mathrm{Ap}^{\mathrm{r}}, 4.2-\mathrm{kb}$ fragment containing $h r p L$ flanking region in pBluescript $\mathrm{SK}(+/-)$ & This work \\
\hline pBS $\Delta h r p L:: g f p-c m$ & $\mathrm{Ap}^{\mathrm{r}}, \mathrm{Cm}^{\mathrm{r}}, 8.3-\mathrm{kb}$ fragment containing $\Delta h r p L:: g f p-\mathrm{cm}$ in pBluescript $\mathrm{SK}(+/-)$ & This work \\
\hline pTALand AD & $\mathrm{Ap}^{\mathrm{r}}, 2.8 \mathrm{~kb}$ of Eca2019 and $h r p S$ regions in pGEM-T Easy & This work \\
\hline pTALand_AD:: $g f p-c m$ & $\mathrm{Ap}^{\mathrm{r}}, \mathrm{Cm}^{\mathrm{r}}, 7 \mathrm{~kb}$ of Eca2019 and $h r p S$ regions in pGEM-T Easy & This work \\
\hline p519nGFP & $\mathrm{Ap}^{\mathrm{r}}$, gfp with $n p t I I$ promoter & Matthysse et al. 1996 \\
\hline
\end{tabular}

\footnotetext{
${ }^{a} \mathrm{Sp}^{\mathrm{r}}, \mathrm{Ap}^{\mathrm{r}}, \mathrm{Cm}^{\mathrm{r}}$, and $\mathrm{Km}^{\mathrm{r}}$ indicate resistance to spectinomycin, ampicillin, chloramphenicol, and kanamycin, respectively; $\mathrm{GFP}=$ green fluorescent protein
} 


\section{MATERIALS AND METHODS}

Bacterial strains.

Bacterial strains used in this study are listed in Table 2. $P$. carotovorum strains were grown in Luria-Bertani (LB) medium at $37^{\circ} \mathrm{C}$ and Pseudomonas syringae strains were grown in King's B (KB) medium at $30^{\circ} \mathrm{C}$ (King et al. 1954). When required, antibiotics were used at the following concentrations: ampicillin $(100 \mu \mathrm{g} / \mathrm{ml})$, chloramphenicol $(20 \mu \mathrm{g} / \mathrm{ml})$, spectinomycin $(50 \mu \mathrm{g} / \mathrm{ml})$, and kanamycin $(50 \mu \mathrm{g} / \mathrm{ml})$.

\section{Construction of Pectobacterium carotovorum mutants.}

To construct plasmids for allelic-exchange mutagenesis of $h r p L, 2.5-$ and 1.7-kb flanking regions of $h r p L$ were PCR amplified with the primer sets listed in Table 3 (Integrated DNA Technologies, Inc., Coralville, IA, U.S.A.) and cloned into the pGEM-T Easy vector (Promega Corp., Madison, WI, U.S.A.), resulting in plasmids pTA $\Delta h r p L \_A B$ and pTA $\triangle h r p L \_C D$. A $1.7-\mathrm{kb}$ fragment was released from pTA $\Delta h r p L \_C D$ with $N o t \mathrm{I}$ and $S a c \mathrm{I}$ and subcloned into the same sites of the pBluescript SK(+/-) vector (Stratagene, Cedar Creek, TX, U.S.A.), yielding plasmid pBS $\Delta h r p L \_C D$. Plasmid pBS $\Delta h r p L$ was constructed by releasing a $2.5-\mathrm{kb}$ fragment from plasmid pTA $\Delta h r p L \_$AB with NotI and SpeI and subcloning the fragment into the same sites of pBS $\Delta h r p L \_C D$. Finally, a cassette encoding chloramphenicol resistance (Datsenko and Wanner 2000) and the GFP (Matthysse et al. 1996.) was cloned into the NotI site of
pBS $\Delta h r p L$, which was located at the junction of 2.5- and 1.7$\mathrm{kb}$ fragments. The final construct was named $\mathrm{pBS} \Delta h r p L:: g f p-$ $\mathrm{cm}$ (Table 2). This plasmid was electrotransformed into wildtype WPP14 for allelic-exchange mutagenesis following the methods described by Ried and Collmer (1987).

Essentially the same procedure was used to construct mutations in $h r p N, h r p K, h r p W, h r p W \_d s p E / F$, and $d s p E / F$. The primers used to amplify chromosomal DNA used to construct plasmids used for allelic exchange when constructing these mutants are listed in Table 3. The double mutation of $h r p L$ and outD was generated by allelic exchange after the transformation of pB $\Delta h r p L:: g f p-c m$ into WPP14 $\Delta$ outD. A $g f p:: c m$-labeled WPP14 was constructed by recombination of $\mathrm{gfp}: \mathrm{cm}$ into a site between two convergently encoded genes, hrpS and Eca2091. A two-step crossover PCR was employed to introduce the adapter for the marker insertion. In the first PCR step, primer sets P0508/P0509 and P0510/P0511 (Table 3) were used in separate reactions to amplify Eca2091 and $h r p S$ regions. In the second PCR step, primers P0508 and P0511 were used to amplify a 2.8-kb fusion of the amplicons from PCR step one. A unique HindIII enzyme site was engineered into primers P0509 and P0510, allowing cleavage and ligation of the gfp::cm marker. The fusion PCR product was cloned into the pGEM-T Easy vector, producing pTALand_AD. The gfp::cm fusion was inserted in pTALand_AD, producing pTALand:: gfp::cm (Table 2). pTALand::gfp::cm was recombined into a neutral chromosomal site between Eca2019 and hrpS by the allelic exchange as described above. The plasmid p519nGFP

Table 3. Oligonucleotides used in this study

\begin{tabular}{|c|c|c|c|}
\hline Primer & Sequence $\left(5^{\prime} \rightarrow 3^{\prime}\right)$ & Restriction sites & Amplified region \\
\hline $\mathrm{P} 0385$ & attagggaatgagctccttgctaacgacg & SacI & $\ldots$ \\
\hline P0386 & gcgtactctgcgaagcttcettcgtcaggecgtagaatcc & HindIII & 2.5-kb hrpL flanking \\
\hline P0387 & ggacgcttcgcagagtacgcttccatttgctgactctccg & HindIII & $\ldots$ \\
\hline P0388 & cggataaggagctcccatgaatctgttgat & SacI & 1.7-kb hrpL flanking \\
\hline P0389 & atccttgagctccacgtccgatgtgc & SacI & $\ldots$ \\
\hline P0390 & cgtactctgcgaagettccattgatgcggcgatgattgg & HindIII & 1.5-kb $h r p N$ flanking \\
\hline P0391 & ggaagcttcgcagagtacgatttgcagagaagctccgcc & HindIII & $\ldots$ \\
\hline P0392 & cgccgtgagctcctgtttattctgacg & SacI & 1.5-kb $h r p N$ flanking \\
\hline $\mathrm{P} 0463$ & tggcgagctcgttcaggcagtaat & SacI & $\ldots$ \\
\hline P0464 & cgtactctgcgaagcttccactaacggtgggcaacaaggta & HindIII & 1.2-kb $h r p W$ flanking \\
\hline P0465 & ggaagcttcgcagagtacgcagtcctgcgecgggttgtatgct & $\ldots$ & $\ldots$ \\
\hline P0466 & cattcagttccggcgtgcta & HindIII & 1.2-kb $h r p W$ flanking \\
\hline P0504 & gtgctggatccgctaatatcatcatac & BamHI & $\ldots$ \\
\hline $\mathrm{P} 0505$ & cgtactctgcgaagcttccegtccecattctgctgttgtca & HindIII & 1.5-kb $h r p K$ flanking \\
\hline P0506 & ggagcttcgcagagtacgattcccaaaccgcgctaatgc & HindIII & $\ldots$ \\
\hline P0507 & gtctgccggatccacgtttaacgat & BamHI & 1.4-kb $h r p K$ flanking \\
\hline P0508 & caccggattgtggttcagacttg & $\ldots$ & $\ldots$ \\
\hline P0509 & cgtactctgcgagacttccacaccgtttctctctacaccg & HindIII & 1.5-kb ADT-0002850 \\
\hline P0510 & ggaagcttcgcagagtacgaaacaggcctgccatcttcag & $\ldots$ & $\ldots$ \\
\hline $\mathrm{P} 0511$ & attggcctgcgttatgcggagaaa & HindIII & $1.3 \mathrm{~kb}$ of $h r p S$ \\
\hline $\mathrm{P} 0753$ & gccetgagcgctactgttggtg & $\ldots$ & $\ldots$ \\
\hline P0795 & cgtactctgegggatccccagtcctggetcttcactgaactgc & BamHI & 1.3-kb $h r p W$ flanking \\
\hline P0796 & ggggatccegcagagtacgggettattaccacggttcatcgcg & $\ldots$ & $\ldots$ \\
\hline P0756 & tccgectgccgetgctgaa & BamHI & 1.3-kb $d s p E$ flanking \\
\hline P0508 & caccggattgtggttcagacttg & $\ldots$ & $\ldots$ \\
\hline P0509 & cgtactctgcgagacttccacaccgtttctctctacaccg & HindIII & $1.5 \mathrm{~kb}$ of Eca2091 \\
\hline P0510 & ggaagcttcgcagagtacgaaacaggcctgccatcttcag & $\ldots$ & $\ldots$ \\
\hline P0511 & attggcctgcgttatgcggagaaa & HindIII & $1.3 \mathrm{~kb}$ of $h r p S$ \\
\hline P0437 & cggcgtctcaacattccagaag & $\ldots$ & $\ldots$ \\
\hline P0438 & ttggcaacaagtggcgtgat & $\ldots$ & 863 bp of $h r p L$ \\
\hline P0437 & cggegtctcaacattccagaag & $\ldots$ & $\ldots$ \\
\hline \multirow[t]{5}{*}{ P0438 } & ttggcaacaagtggcgtgat & $\ldots$ & 863 bp of $h r p L$ \\
\hline & tgcccettccacctggtt & $\ldots$ & $\ldots$ \\
\hline & ggcaacaccacacgttcttg & $\ldots$ & 48 bp of $N b M A P K K K$ \\
\hline & cgctctcaaagtcatctacggtaa & $\ldots$ & $\ldots$ \\
\hline & aatctcgatctcacggcacat & $\ldots$ & 51 bp of $N b M E K 2$ \\
\hline $\mathrm{P} 0751$ & caatcagcctgggaagtacca & $\ldots$ & $E F-\alpha$ \\
\hline \multirow[t]{3}{*}{$\mathrm{P} 0752$} & gatgcccccggacaca & $\ldots$ & $\ldots$ \\
\hline & cggcatgcttaacacatgca & $\ldots$ & $\ldots$ \\
\hline & agccgtttccagctgttgttc & $\ldots$ & Ubiquitin \\
\hline
\end{tabular}


(Matthysse et al. 1996.) was electrotransformed into WPP14. Mutations were confirmed by PCR and Southern blot analysis. Transformation, restriction endonuclease digestion, and other DNA manipulations were similar to those described by Sambrook and Russell (2001).

\section{Leaf infiltration assays.}

$N$. benthamiana was grown in growth chambers at $26^{\circ} \mathrm{C}$ with a 12 -h photoperiod under $40-\mathrm{W}$ cool white fluorescent bulbs with photons at $240 \mu \mathrm{mol} / \mathrm{m}^{2} / \mathrm{s}$. Fully expanded leaves of 4- to 5-week-old $N$. benthamiana were infiltrated with bacterial suspensions at $10^{8} \mathrm{CFU} / \mathrm{ml}$ with a needleless $1-\mathrm{ml}$ syringe. The treated plants were placed in a growth chamber under ambient humidity and reactions were recorded at 24 and 48 hpi. Each assay was performed in triplicate and all plant assays were repeated at least three times. For the tetracycline assays used to determine at what time HR elicitation could no longer be inhibited, leaves were co-infiltrated with a $P$. carotovorum WPP14 suspension at $10^{8} \mathrm{CFU} / \mathrm{ml}$ plus tetracycline at 10 or $100 \mu \mathrm{g} / \mathrm{ml}$ to determine whether bacterial gene expression was required for plant cell death. Leaves were also infiltrated with tetracycline at 10 or $100 \mu \mathrm{g} / \mathrm{ml} 3$ hpi to determine whether plant cell death could be inhibited at a later time point.

For virulence assays, $N$. benthamiana plants were grown as described above and potato plants were grown from tubers in the greenhouse. Plant assays were performed essentially as described (Hirano et al. 1997). Leaves from 4- to 6-week-old $N$. benthamiana plants or 3-week-old potato plants were infiltrated with a bacterial suspension of $10^{4} \mathrm{CFU} / \mathrm{ml}$ (potato and $N$. benthamiana) or $10^{6} \mathrm{CFU} / \mathrm{ml}$ (potato). Infected plants were loosely covered with plastic bags to maintain high humidity and incubated in a growth chamber at $25^{\circ} \mathrm{C}(N$. benthamiana) or on a laboratory bench (potato) throughout the course of the assay. To estimate bacterial growth, entire $N$. benthamiana leaves were removed, weighed, and then homogenized at $0,1,2,3$, and 5 days after inoculation. Dilution plating onto LB agar (LBA) plus appropriate antibiotics was used to estimate CFU of bacteria per gram leaf. Three leaves per time point per strain were assayed and the experiment was repeated three times. For potato, $1-\mathrm{cm}^{2}$ leaf disks were removed from the infiltrated leaf and homogenized in a 1.7$\mathrm{ml}$ tube, and the suspension was dilution plated onto LBA medium plus appropriate antibiotics. The potato assay was repeated twice, with five leaves per rep.

\section{Callose deposition and GFP assays.}

Callose deposition in $N$. benthamiana was assayed with a protocol described by Hann and Rathjen (2007). Briefly, bacterial cells were grown on LB or KB agar with appropriate antibiotics, washed once in sterile water, and then resuspended at $10^{8} \mathrm{CFU} / \mathrm{ml}$. $N$. benthamiana leaves were infiltrated with the bacterial suspension and collected at 6 and 24 hpi. The harvested leaf discs were cleared of pigment by incubation in $95 \%$ ethanol at $37^{\circ} \mathrm{C}$ followed by two washes with $70 \%$ ethanol. Cleared leaf discs were subsequently vacuum infiltrated with aniline blue solution $(0.01 \%$ aniline blue in $150 \mathrm{mM}$ $\mathrm{K}_{2} \mathrm{HPO}_{4}, \mathrm{pH}$ 9.5) overnight, in the dark. Aniline-blue-stained leaf discs were mounted in $60 \%$ glycerol and examined with a BX60 epifluorescence microscope (Olympus America, Inc., Melville, NY, U.S.A.) with an excitation filter of $365 \pm 25 \mathrm{~nm}$, a 400-nm dichroic mirror, and a 450-nm long-pass emission filter. Images were captured as monochrome images with a Magnafire camera (Optronics, Goleta, CA, U.S.A.) and Image Pro Plus software (MediaCybernetics, Silver Spring, MD, U.S.A.). The images were false colored with Photoshop CS3 (Adobe Systems, Inc., San Jose, CA, U.S.A.). Each assay was performed in triplicate with at least three leaf discs collected per treated leaf. All callose deposition assays were repeated at least three times.

WPP14(p519nGFP) was infiltrated at $10^{7} \mathrm{CFU} / \mathrm{ml}$ into the leaves of 4- to 5-week-old $N$. benthamiana using a needleless syringe. The infiltrated leaves were observed by epifluorescence microscopy to monitor GFP-labeled cells as described above, except that an excitation filter of $488 \pm 10 \mathrm{~nm}$, a >500$\mathrm{nm}$ dichroic mirror, and a 520-nm long-pass emission filter were used.

\section{qPCR analysis.}

Total RNA from $N$. benthamiana leaves at 3 hpi was extracted from using Trizol reagent (Invitrogen, Carlsbad, CA, U.S.A.) followed by cleanup step using the RNeasy mini kit (Qiagen, Valencia, CA, U.S.A.). The total RNA was treated with DNase I and examined for quality with an Agilent 2100 bioanalyzer (Agilent Technologies, Santa Clara, CA, U.S.A.). First-strand cDNA was synthesized with the SuperScript III First-Strand Synthesis System for RT-PCR following the manufacturer's protocol (Invitrogen). Oligo $(\mathrm{dT})_{20}$ was used as primer, and treated and extracted total RNA $(1 \mu \mathrm{g})$ was used as template. Primers specific to NbMAPKKK, NbMEK2, Ubiquitin, or $N$. benthamiana EF1- $\alpha$ were designed with Primer Expression 2.0 (Applied Biosystems, Foster City, CA, U.S.A.) (Table 3). Real-time PCR was performed with ABI 7300 Fast Real-Time PCR System (Applied Biosystems) using SYBR Green I with the following conditions: $95^{\circ} \mathrm{C}$ for $3 \mathrm{~min} ; 40$ cycles of $95^{\circ} \mathrm{C}$ for $15 \mathrm{~s}, 56^{\circ} \mathrm{C}$ for $30 \mathrm{~s}$, and $72^{\circ} \mathrm{C}$ for $30 \mathrm{~s}$; followed by a melting cycle of 55 to $95^{\circ} \mathrm{C}$ with an increasing gradient of $0.5^{\circ} \mathrm{C}$ and a 10 -s pause at each temperature. All reactions were performed in duplicate. Data processing was done with the ABI 73000 real-time PCR system software (version 1.4). EF1- $\alpha$ and ubiquitin mRNAs were quantified as internal controls to normalize the transcript levels of target genes. The fold differences were calculated with the $\Delta \Delta$ cycle threshold method (Livak and Schmittgen 2001). All qRT-PCR experiments were repeated twice.

\section{$N$. benthamiana microarray design.}

The Nimblegen microarray is composed of 13,415 unigene $N$. benthamiana EST representing an estimated $38 \%$ of the transcriptome. The $N$. benthamiana sequences composing the array were compiled from five distinct EST libraries: expanding leaf tissue manufactured by Amplicon Express, Inc. (Pullman, WA, U.S.A.); green aerial parts of the plant created in A. Maule's laboratory at the John Innes Centre (Norwich, U.K.); a subtraction library of healthy plants against Colletotrichum destructivum-infected $N$. benthamiana donated by P. Goodwin from the University of Guelph (Guelph, ON Canada); EST sequences derived from a search of TIGR; and GenBank databases. The unigene set was collated from these 40,000 individual EST and the sequences were submitted to NimbleGen Systems, Inc. (Roche NimbleGen, Madison, WI, U.S.A.) to customize a oligonucleotide-based microarray which was designed to consist of 60-mers probe, and each EST consisted of nine different probes, repeated three times, on the array (Feulner 2007).

The Blast2GO (Conesa et al. 2005) software was applied to assign the functionality information of genes representing on this array. The sequences were subjected to an NR database of GenBank search using BLASTX (Altschul et al. 1990) and only similarities with expected value $(E)$ smaller or equal to $10^{-5}$ were further classified into categories according to a gene ontology scheme; cellular component, biological process, and molecular function (Ashburner et al. 2000). 
RNA isolation, processing, and cDNA array hybridization.

Transcriptomic analysis was performed with a customdesigned oligonucleotide array (Roche NimbleGen; NimbleGen Systems Inc.) and three biological replicates were analyzed for each bacterial treatment. The arrays consisted of 60 -mer probe pairs representing $13,415 \mathrm{~N}$. benthamiana transcripts. $N$. benthamiana leaves (4 to 5 weeks old) were infiltrated with a bacterial suspension at of WPP14, WPP14 $h r p L$, WPP14 $1 s p E / F, P s e u-$ domonas syringae pv. tomato DC3000, or DC3000 $\Delta h r c$ at $10^{8}$ $\mathrm{CFU} / \mathrm{ml}$. Untreated leaves and leaves infiltrated with $\mathrm{dH}_{2} \mathrm{O}$ were used as controls. After $3 \mathrm{~h}$, all fully expanded leaves for each bacterial treatment were harvested, frozen in liquid $\mathrm{N}_{2}$, and stored at $-80^{\circ} \mathrm{C}$ for subsequent RNA isolation. The total RNA from $N$. benthamiana leaves was isolated using Trizol reagent (Invitrogen) and an RNeasy Mini Kit (Qiagen). The quality and concentration of RNA samples were verified using Agilent 2100 Bioanalyzer with a RNA6000 NanoChip (Agilent Technologies) and spectrophotometric analysis (NanoDrop ND-1000; NanoDrop Technologies, Wilmington, DE, U.S.A.). cDNA synthesis and labeling were performed using the Amino Allyl MessageAmp II aRNA amplification kit (Ambion, Austin, TX, U.S.A.) according to the manufacturer's instructions. In brief, first- and second-strand cDNA was synthesized from $2 \mu \mathrm{g}$ of total RNA. The purified cDNA was synthesized to amino allylmodified aRNA by in vitro transcription and then the aRNA was labeled with amine-reactive $\mathrm{Cy} 3$ or $\mathrm{Cy} 5$ dyes. The mixture of 3 $\mu \mathrm{g}$ of each labeled aRNA was hybridized for $17 \mathrm{~h}$ at $45^{\circ} \mathrm{C}$ to the $N$. benthamiana 4-plex NimbleExpress GeneChip array according to the NimbleGen Gene Expression Protocol; each biological replicate for each bacterial treatment was hybridized at least twice with a dye swap. Arrays were scanned at wavelengths of 532 and $635 \mathrm{~nm}$ using an Axon 4000B scanner (Molecular Devices Corporation, Union City, CA, U.S.A.) and the data were analyzed using NimbleScan software.

\section{Microarray data analysis and statistical methods.}

Microarray data analyses were performed using Partek Genomics Suite software (version 6.4; Partek Incorporated, St. Louis) (Fig. 6). Raw hybridization signals were normalized using the quantile normalization method to make distributions of signal intensities uniform across chips (Bolstad et al. 2003). The probe-signal intensity $\left(\log _{2}\right)$ was analyzed using robust multichip average with the 13,415-gene set (Irizarry et al. 2003). Multiple ANOVA included the following factors: five bacterial treatments, Cy3-Cy5 labeling method, three biological replicates, and the interaction between bacterial treatments and labeling method. FDR was performed to correct false positives for multiple test corrections for $P$ values calculated from ANOVA (Benjamini and Hochberg 1995). The DEG were listed based on a $P$-value cutoff calculated from the significant levels of 0.05 or $0.01 \mathrm{FDR}$, which were then visualized on a heat map and hierarchical clustering with Euclidian distance (Pawitan et al. 2005). Microarray data were deposited with the National Center for Biotechnology Information Gene Expression Omnibus under accession number E-TABM-752.

\section{ACKNOWLEDGMENTS}

We thank the National Science Foundation Genomics in the Environment Program (award number 0412599) and the Royal Thai Government (Thailand) for funding this work; M.-N. Yap for constructing pTA::gfp-cm; and the reviewers for their helpful comments.

\section{LITERATURE CITED}

Abramovitch, R. B., Anderson, J. C., and Martin, G. B. 2006. Bacterial elicitation and evasion of plant innate immunity. Nat. Rev. 7:601-611.

Ahn, I.-P. 2007. Disturbance of the $\mathrm{Ca}^{2+} /$ calmodulin-dependent signalling pathway is responsible for the resistance of Arabidopsis dndl against Pectobacterium carotovorum infection. Mol. Plant Pathol. 8:747-759.

Alto, N. M. 2008. Mimicking small G-proteins: An emerging theme from the bacterial virulence arsenal. Cell. Microbiol. 10:566-575.

Alto, N. M., Shao, F., Lazar, C. S., Brost, R. L., Chua, G., Mattoo, S., McMahon, S. A., Ghosh, P., Hughes, T. R., Boone, C., and Dixon, J. E. 2006. Identification of a bacterial type III effector family with $\mathrm{G}$ protein mimicry functions. Cell 124:133-145.

Altschul, S. F., Gish, W., Miller, W., Myers, E. W., and Lipman, D. J. 1990. Basic local alignment search tool. J. Mol. Biol. 215:403-410.

Aranda, S., Montes-Borrego, M., Munoz-Ledesma, F. J., Jimenez-Diaz, R. M., and Landa, B. B. 2008. First report of Pectobacterium carotovorum causing soft rot of opium poppy in Spain. Plant Dis. 92:317.

Asai, S., Ohta, K., and Yoshioka, H. 2008. MAPK signaling regulates nitric oxide and NADPH oxidase-dependent oxidative bursts in Nico tiana benthamiana. Plant Cell 20:1390-1406.

Asai, T., Tena, G., Plotnikova, J., Willmann, M. R., Chiu, W. L., GomezGomez, L., Boller, T., Ausubel, F. M., and Sheen, J. 2002. MAP kinase signalling cascade in Arabidopsis innate immunity. Nature 415:977983.

Ashburner, M., Ball, C. A., Blake, J. A., Botstein, D., Butler, H., Cherry, J. M., Davis, A. P., Dolinski, D., Dwight, S. S., Eppig, J. T., Harris, M. A., Hill, D. P., Issel-Tarver, L., Kasarskis, A., Lewis, S., Matese, J. C., Richardson, J. E., Ringwald, M., Rubin, G. M., and Scherlock, G. 2000. Gene ontology: Tool for the unification of biology. The Gene Ontology Consortium. Nat. Genet. 25:25-29.

Barabote, R. D., Johnson, O. L., Zetina, E., San Francisco, S. K., Fralick, J. A., and San Francisco, M. J. D. 2003. The Erwinia chrysanthemi tolC is involved in resistance to antimicrobial plant chemicals and is essential for phytopathogenesis. J. Bacteriol. 185:5772-5778.

Bell, K. S., Sebaihia, M., Pritchard, L., Holden, M. T. G., Hyman, L. J., Holeva, M. C., Thomson, N. R., Bentley, S. D., Churcher, L. J. C., Mungall, K., Atkin, R., Bason, N., Brooks, K., Chillingworth, T., Clark, K., Doggett, J., Fraser, A., Hance, Z., Hauser, H., Jagels, K., Moule, S., Norbertczak, H., Ormond, D., Price, C., Quail, M. A., Sanders, M. Walker, D., Whitehead, S., Salmond, G. P. C., Birch, P. R. J., Parkhill, J., and Toth, I. K. 2004. Genome sequence of the enterobacterial phytopathogen Erwinia carotovora subsp. atroseptica and characterization of virulence factors. Proc. Natl. Acad. Sci. U.S.A. 101:11105-11110.

Benjamini, Y., and Hochberg, Y. 1995. Controlling the false discovery rate-a practical and powerful approach to multiple testing. J. R. Stat. Soc. Ser. B 57:289-300

Bent, A. F., and Mackey, D. 2007. Elicitors, effectors, and $R$ genes: The new paradigm and a lifetime supply of questions. Annu. Rev. Phytopathol. 45:399-436.

Bhattarai, K. K., Atamian, H. S., Kaloshian, I., and Eulgem, T. 2010. WRKY72-type transcription factors contribute to basal immunity in tomato and Arabidopsis as well as gene-for-gene resistance mediated by the tomato $R$ gene $M i-1$. Plant J. 63:229-240.

Bogdanove, A. J., Bauer, D. W., and Beer, S. V. 1998a. Erwinia amylovora secretes DspE, a pathogenicity factor and functional AvrE homolog, through the Hrp (type III secretion) pathway. J. Bacteriol. 180:22442247.

Bogdanove, A. J., Kim, J. F., Wei, Z., Kolchinsky, P., Charkowski, A. O., Conlin, A. K., Collmer, A., and Beer, S. V. 1998b. Homology and functional similarity of an $h r p$-linked pathogenicity locus, $d s p E F$, of $E r$ winia amylovora and the avirulence locus avrE of Pseudomonas syringae pathovar tomato. Proc. Natl. Acad. Sci. USA 95:1325-1330.

Bolstad, B. M., Irizarry, R. A., Astrand, M., and Speed, T. P. 2003. A comparison of normalization methods for high density oligonucleotide array data based on variance and bias. Bioinformatics 19:185-193

Boureau, T., El Maarouf-Boteau, H., Garnier, A., Brisset, M.-N., Perino, C., Pucheu, I., and Barny, M. A. 2005. DspA/E, a type III effector essential for Erwinia amylovora pathogenicity and growth in planta, induces cell death in host apple and non-host tobacco plants. Mol. PlantMicrobe Interact. 19:16-24.

Chatterjee, A., Cui, Y. Y., and Chatterjee, A. K. 2002. Regulation of Erwinia carotovora hrpL(Ecc) (sigma-L-Ecc), which encodes an extracytoplasmic function subfamily of sigma factor required for expression of the HRP regulon. Mol. Plant-Microbe Interact. 15:971-980.

Chisholm, S. T., Coaker, G., Day, B., and Staskawicz, B. J. 2006. Host-microbe interactions: Shaping the evolution of the plant immune response. Cell 124:803-814.

Conesa, A., Gotz, S., Garcia-Gomez, J., Terol, J., Talon, M., and Robles, M. 2005. Blast2GO: A universal tool for annotation, visualization and analysis in functional genomics research. Bioinformatics 21:3674.

Datsenko, K. A., and Wanner, B. L. 2000. One-step inactivation of chromosomal genes in Escherichia coli K-12 using PCR products. Proc. Natl. Acad. Sci. U.S.A. 97:6640-6645.

DebRoy, S., Thilmony, R., Kwack, Y. B., Nomura, K., and He, S. Y. 2004. 
A family of conserved bacterial effectors inhibits salicylic acid-mediated basal immunity and promotes disease necrosis in plants. Proc. Natl. Acad. Sci. U.S.A. 101:9927-9932.

del Pozo, O., Pedley, K. F., and Martin, G. B. 2004. MAPKKK alpha is a positive regulator of cell death associated with both plant immunity and disease. EMBO (Eur. Mol. Biol. Organ.) J. 23:3072-3082

Expert, D. 1999. Withholding and exchanging iron: Interactions between Erwinia spp. and their plant hosts. Annu. Rev. Phytopathol. 37:307-334.

Fagard, M., Dellagi, A., Roux, C., Perino, C., Rigault, M., Boucher, V., Shevchik, V. E., and Expert, D. 2007. Arabidopsis thaliana expresses multiple lines of defense to counterattack Erwinia chrysanthemi. Mol. Plant-Microbe Interact. 20:794-805

Fellay, R., Frey, J., and Krisch, H. 1987. Interposon mutagenesis of soil and water bacteria: A family of DNA fragments designed for in vitro insertional mutagenesis of gram-negative bacteria. Gene 52:147-154.

Feulner, G. 2007. The Modulation of Nicotiana benthamiana Gene Expression by Red clover necrotic mosaic virus. North Carolina State University, Raleigh, NC, U.S.A.

Gardan, L., Gouy, C., Christen, R., and Samson, R. 2003. Elevation of three subspecies of Pectobacterium carotovorum to species level: Pectobacterium atrosepticum $\mathrm{sp}$ nov., Pectobacterium betavasculorum $\mathrm{sp}$ nov. and Pectobacterium wasabiae sp nov. Int. J. Syst. Evol. Microbiol. 53:381-391.

Gaudriault, S., Malandrin, L., Paulin, J.-P., and Barny, M.-A. 1997. DspA, an essential pathogenicity factor of Erwinia amylovora showing homology with AvrE of Pseudomonas syringae, is secreted via the Hrp secretion pathway in a DspB-dependent way. Mol. Microbiol. 26:1057-1069.

Gaudriault, S., Paulin, J.-P., and Barny, M.-A. 2002. The DspB/F protein of Erwinia amylovora is a type III secretion chaperone ensuring efficient intrabacterial production of the Hrp-secreted DspA/E pathogenicity factor. Mol. Plant Pathol. 3:313-320.

Glasner, J. D., Rusch, M., Liss, P., Plunkett, G., 3rd, C., E. L., Darling, A., Anderson, B. D., Infield-Harm, P., Gilson, M. C., and Perna, N. T. 2006. ASAP: A resource for annotating, curating, comparing, and disseminating genomic data. Nucleic Acids Res. 34:D41-45.

Glasner, J. D., Marquez-Villavicencio, M., Kim, H.-S., Jahn, C. E., Ma, B., Biehl, B. S., Rissman, A. I., Mole, B., Yi, X., Yang, C.-H., Dangl, J. L., Grant, S. R., Perna, N. T., and Charkowski, A. O. 2008. Niche-specificity and the variable fraction of the Pectobacterium pan-genome. Mol. Plant-Microbe Interact. 21:1549-1560.

Glazebrook, J. 2005. Contrasting mechanisms of defense against biotrophic and necrotrophic pathogens. Annu. Rev. Phytopathol. 43:205-227.

Govrin, E. M., and Levine, A. 2000. The hypersensitive response facilitates plant infection by the necrotrophic pathogen Botrytis cinerea. Curr. Biol. 10:751-757.

Grant, S. R., Fisher, E. J., Chang, J. H., Mole, B. M., and Dangl, J. L. 2006. Subterfuge and manipulation: Type III effector proteins of phytopathogenic bacteria. Annu. Rev. Microbiol. 60:425-449.

Ham, J. H., Majerczak, D. R., Arroyo-Rodriguez, A. S., Mackey, D. M., and Coplin, D. L. 2006. WtsE, an AvrE-family effector protein from Pantoea stewartii subsp. stewartii, causes disease-associated cell death in corn and requires a chaperone protein for stability. Mol. Plant-Microbe Interact. 19:1092-1102.

Ham, J. H., Majerczak, D. R., Ewert, S., Sheehekha, M.-V., Mackey, D., and Coplin, D. 2008. WtsE, an AvrE-family type III effector protein of Pantoea stewartii subsp. stewartii, causes cell death in non-host plants Mol. Plant Pathol. 9:633-643.

Ham, J. H., Majerczak, D. R., Nomura, K., Mecey, C., Uribe, F., He, S. Y., Mackey, D., and Coplin, D. L. 2009. Multiple activities of the plant pathogen type III effector proteins WtsE and AvrE require WxxxE motifs. Mol. Plant-Microbe Interact. 22:703-712.

Hann, D. R., and Rathjen, J. P. 2007. Early events in the pathogenicity of Pseudomonas syringae on Nicotiana benthamiana. Plant J. 49:607618

Hauck, P., Thilmony, R., and He, S. Y. 2003. A Pseudomonas syringae type III effector suppresses cell wall-based extracellular defense in susceptible Arabidopsis plants. Proc. Natl. Acad. Sci. U.S.A. 100:85778582.

He, P., Shan, L., Lin, N. S., Martin, G. B., Kemmerling, B., Nurnberger, T., and Sheen, J. 2006. Specific bacterial suppressors of MAMP signaling upstream of MAPKKK in Arabidopsis innate immunity. Cell 125:563-575.

Hirano, S. S., Osterag, E. M., Savage, S. A., Baker, L. S., Willis, D. K., and Upper, C. D. 1997. Contribution of the regulatory gene lemA to field fitness of Pseudomonas syringae pv. syringae. Appl. Environ. Microbiol. 63:4304-4312.

Holeva, M. C., Bell, K. S., Hyman, L. J., Avrova, A. O., Whisson, S. C., Birch, P. R. J., and Toth, I. K. 2004. Use of a pooled transposon mutation grid to demonstrate roles in disease development for Erwinia carotovora subsp. atroseptica putative type III secreted effector (DspE/A) and helper $(\mathrm{HrpN})$ proteins. Mol. Plant-Microbe Interact. 17:943-950.

Irizarry, R. A., Hobbs, B., Collin, F., Beazer-Barclay, Y. D., Antonellis, K. J., Scherf, U., and Speed, T. P. 2003. Exploration, normalization, and summaries of high density oligonucleotide array probe level data. Bioinformatics 19:249-264.

Jacobs, A. K., Lipka, V., Burton, R. A., Panstruga, R., Strizhov, N., SchulzeLefert, P., and Fincher, G. B. 2003. An Arabidopsis callose synthase, GSL5, is required for wound and papillary callose formation. Plant Cell $15: 2503-2513$

Jones, J. D. G., and Dangl, J. L. 2006. The plant immune system. Nature 444:323-329.

Kim, H.-S., Ma, B., Perna, N. T., and Charkowski, A. O. 2009. Prevalence and virulence of natural type III secretion system deficient Pectobacterium strains. Appl. Environ. Microbiol. 75:4539-4549.

Kim, M. G., da Cunha, L., McFall, A. J., Belkhadir, Y., DebRoy, S., Dangl, J. L., and Mackey, D. 2005. Two Pseudomonas syringae type III effectors inhibit RIM-regulated basal defense in Arabidopsis. Cell 121:749759.

King, E. O., Ward, M. K., and Raney, D. E. 1954. Two simple media for the demonstration of pyocyanin and fluorescein. J. Lab. Med. 22:301307.

Livak, K. J., and Schmittgen, T. D. 2001. Analysis of relative gene expression data using real-time quantitative PCR and the $2^{-\Delta \Lambda \mathrm{CT}}$ method. Methods 25:402-408.

Lopez-Solanilla, E., Garcia-Olmedo, F., and Rodriguez-Palenzuela, P. 1998. Inactivation of the sapA to sapF locus of Erwinia chysanthemi reveals common features in plant and animal bacterial pathogenesis. Plant Cell 10:917-924.

Ma, B., Hibbing, M. E., Kim, H.-S., Reedy, R. M., Yedidia, I., Breuer, J., Breuer, J., Glasner, J. D., Perna, N. T., Kelman, A., and Charkowski, A O. 2007. The host range and molecular phylogenies of the soft rot enterobacterial genera Pectobacterium and Dickeya. Phytopathology 97:1150-1163.

Marits, R., Koiv, V., Laasik, E., and Mae, A. 1999. Isolation of an extracellular protease gene of Erwinia carotovora subsp. carotovora strain SCC3193 by transposon mutagenesis and the role of protease in phytopathogenicity. Microbiology 145:1959-1966.

Marits, R., Tshuikina, M., Pirhonen, M., Laasik, E., and Mae, A. 2002 Regulation of the expression of prtW::gusA fusions in Erwinia carotovora subsp. carotovora. Microbiology 148:835-842.

Matthysse, A. G., Stretton, S., Dandie, C., McClure, N. C., and Goodman, A. E. 1996. Construction of GFP vectors for use in gram-negative bacteria other than Escherichia coli. FEMS (Fed. Eur. Microbiol. Soc.) Microbiol. Lett. 145:87-94.

Munkvold, K. R., Martin, M. E., Bronstein, P. A., and Collmer, A. 2008. A survey of the Pseudomonas syringae pv. tomato DC3000 type III secretion system effector repertoire reveals several effectors that are deleterious when expressed in Saccharomyces cerevisiae. Mol. Plant-Microbe Interact. 21:490-502.

Nishimura, M. T., Stein, M., Hou, B. H., Vogel, J. P., and Edwards, H. S., S. C. 2003. Loss of a callose synthase results in salicylic acid-dependent disease resistance. Science 301:969-972.

Oh, C.-S., Martin, G. B., and Beer, S. V. 2007. DspA/E, a type III effector of Erwinia amylovora, is required for early rapid growth in Nicotiana benthamiana and causes NbSGT1-dependent cell death. Mol. Plant Pathol. 8:255-265.

Oh, H.-S., and Collmer, A. 2005. Basal resistance against bacteria in Nicotiana benthamiana leaves is accompanied by reduced vascular staining and suppressed by multiple Pseudomonas syringae type III secretion system effector proteins. Plant J. 44:348-359.

Pawitan, Y., Michiels, S., Koscielny, S., Gusnanto, A., and Ploner, A. 2005. False discovery rate, sensitivity and sample size for microarray studies. Bioinformatics 3017-3024.

Perombelon, M. C. M. 2002. Potato diseases caused by soft rot erwinias: An overview of pathogenesis. Plant Pathol. 51:1-12.

Petnicki-Ocwieja, T., van Dijk, K., and Alfano, J. R. 2005. The hrpK operon of Pseudomonas syringae pv. tomato DC3000 encodes two proteins secreted by the type III (Hrp) protein secretion system: HopB1 and HrpK, a putative type III translocator. J. Bacteriol. 187:649-663.

Ried, J. L., and Collmer, A. 1987. An nptI-sacB-sacR cartridge for constructing directed, unmarked mutations in gram-negative bacteria by marker-exchange-eviction mutagenesis. Gene 57:239-246.

Ringnér, M. 2008. What is principal components analysis? Nat. Biotechnol. 26:303-304.

Robertson, D. 2004. VIGS vectors for gene silencing: Many targets, many tools. Annu. Rev. Phytopathol. 55:495-519.

Sambrook, J., and Russell, D. W. 2001. Molecular Cloning. A Laboratory Manual. Cold Spring Harbor Laboratory Press, Cold Spring Harbor, NY, U.S.A.

Thomson, N. R., Thomas, J. D., and Salmond, G. P. C. 1999. Virulence de- 
terminants in the bacterial phytopathogen Erwinia. Methods Microbiol. 29:347-426

Triplett, L. R., Melotto, M., and Sundin, G. W. 2009. Functional analysis of the $\mathrm{N}$ terminus of the Erwinia amylovora secreted effector DspA/E reveals features required for secretion, translocation, and binding to the chaperone DspB/F. Mol. Plant-Microbe Interact. 22:1282-1292.

Valecillos, A. M., Palenzuela, P. R., and Lopez-Solanilia, E. 2006. The role of several multidrug resistance systems in Erwinia chrysanthemi pathogenesis. Mol. Plant-Microbe Interact. 19:607-613.

Vidal, S., deLeon, I. P., Denecke, J., and Palva, E. T. 1997. Salicylic acid and the plant pathogen Erwinia carotovora induce defense genes via antagonistic pathways. Plant J. 11:115-123.

Wang, K., Uppalapati, S. R., Zhu, X., Dinesh-Kumar, S., and Mysore, K. S. 2010. SGT1 positively regulates the process of plant cell death during both compatible and incompatible plant-pathogen interactions. Mol. Plant Pathol. 11:597-611.

Wei, C.-F., Kvitko, B. H., Shimizu, R., Crabill, E., Alfano, J. R., Lin, N.-C., Martin, G. B., Huang, H.-C., and Collmer, A. 2007. A Pseudomonas syringae pv. tomato DC300 mutant lacking the type III effector HopQ1-1 is able to cause disease in the model plant Nicotiana benthamiana. Plant J. 51:32-46.

Willis, D. K., Hrabek, E. M., Rich, J. J., Barta, T. M., Lindow, S. E., and Panapoulos, N. J. 1990. Isolation and characterization of a Pseudomonas syringae pv. syringae mutant deficient in lesion formation on bean. Mol. Plant-Microbe Interact. 3:149-156.

Wydro, M., Kozubek, E., and Lehmann, P. 2006. Optimization of transient Agrobacterium-mediated gene expression system in leaves of Nicotiana benthamiana. Acta Biochim. Pol. 53:289-298.

Yap, M.-N., Barak, J. D., and Charkowski, A. O. 2004. Genomic diversity of Erwinia carotovora subsp. carotovora and its correlation with virulence. Appl. Environ. Microbiol. 70:3013-3023.

Yuan, J., and He, S. Y. 1996. The Pseudomonas syringae Hrp regulation and secretion system controls the production and secretion of multiple extracellular proteins. J. Bacteriol. 178:6399-6402.

Zhang, J., Shao, F., Cui, H., Chen, L. J., Li, H. T., Zou, Y., Long, C. Z. Lan, L. F., Chai, J. J., Chen, S., Tang, X. Y., and Zhou, J. M. 2007. A Pseudomonas syringae effector inactivates MAPKs to suppress PAMPInduced immunity in plants. Cell Host Microbe 1:175-185. 